ISSN 0718 - 4530 Version unpresa

ISSN $0718-4646$ Versión en linea
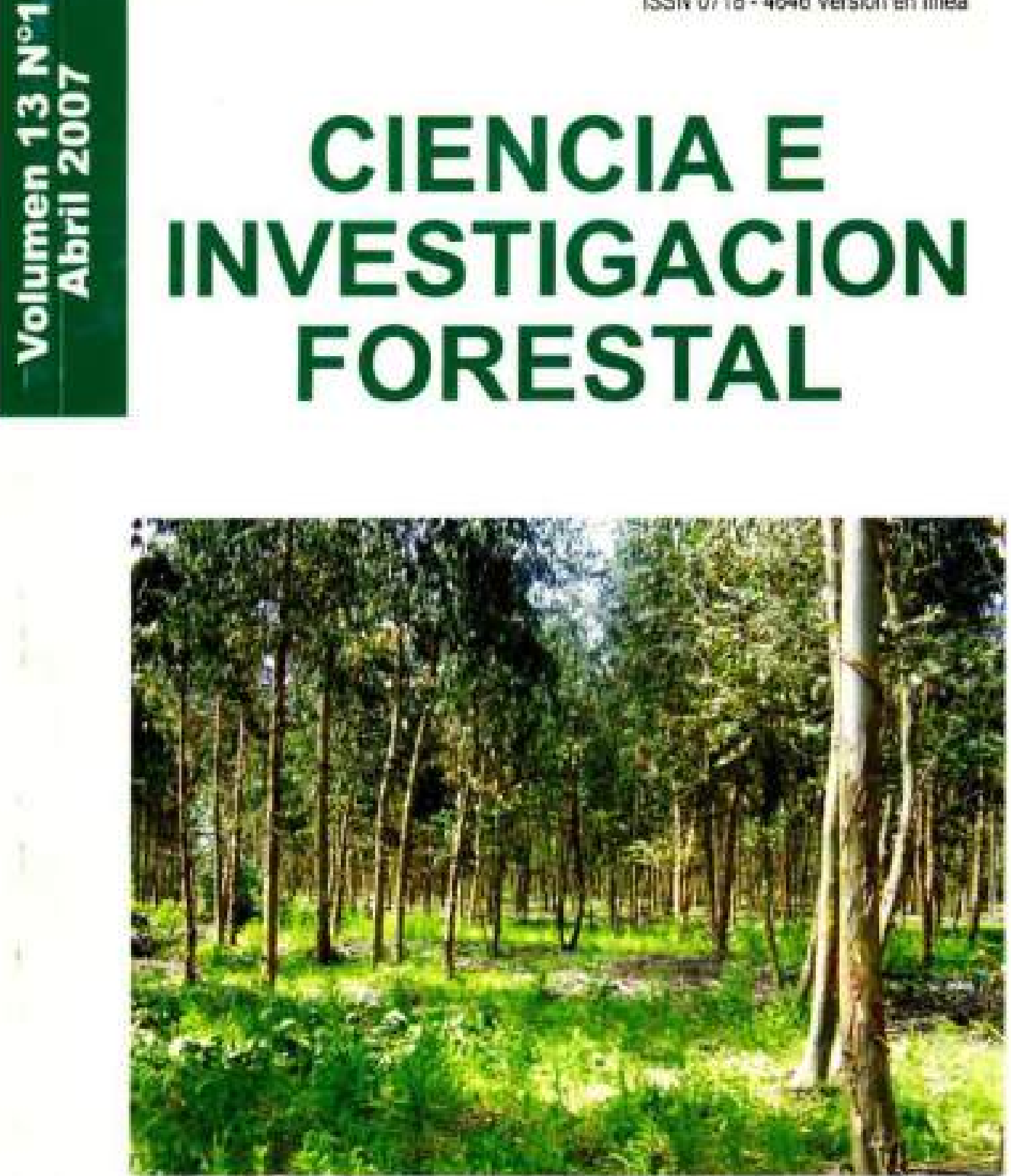

INSTITUTO FORESTAL CHILE

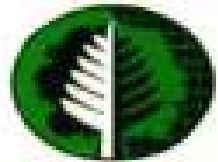




\section{VOLUMEN $13 N^{\circ} 1$}

\section{CIENCIAE INVESTIGACION FORESTAL ABRIL 2007}

Propiedad Intelectual

Registro $\mathrm{N}^{\circ} 46306$

RELACIONES INTERNACIONALES Y COMUNICACIONES INFOR

\section{INSTITUTO FORESTAL \\ CHILE}


CIENCIA E INVESTIGACION FORESTAL es una revista cientifica, arbitrada. periódica y seriads del Instìuto Forestal, Chile, que es publicada en abril, agosto y diciembre do cada año.

Directora

Editar

Consejo Etitior

Camit6 Editar
Marta Abalos Romero

Santiago Barros Aseno

Sandra Perret Duràn

Norberto Parra Hidalgo

Braulie Gutiemez Cora

Jarge Cabrera Perramón

Paulo Moreno Meynart

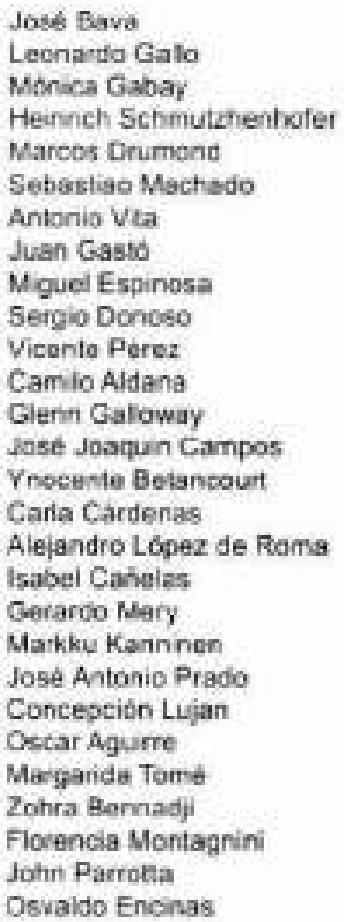

INFOR

INFOR-IUFRO Chile

INFOR La Serena Chile

INFOR Santiago Chile

INFOR Concepeian Chile

INFOR Valdivia Chile

INFOR Coyhaique Chila

\begin{tabular}{|c|c|}
\hline CIEFAP & Argentina \\
\hline INTA & Argentina \\
\hline SAyDS & Argentina \\
\hline UFRO & Austria \\
\hline EMERAPA & Brasi \\
\hline UFPR & Brasi \\
\hline WXCH & Chile \\
\hline PUC & Chile \\
\hline UDEC & Chile \\
\hline $\mathrm{UCH}$ & Chile \\
\hline USACH & Chile \\
\hline CONIF & Colcmba \\
\hline CATE & Costa Rica \\
\hline CATIE & Costa Rica \\
\hline UPR & Cuba \\
\hline MINAMBIENTE - IUFAO & Ecuador \\
\hline INIA & España \\
\hline INIA-IUFAO & España \\
\hline METLA-IUFRO & Fintandia \\
\hline CIFOR & Indonesia \\
\hline FAO & Italaa \\
\hline$\triangle A C H$ & Máxico \\
\hline UANL & Mexice \\
\hline UTL - IUFRO & Portaga \\
\hline NLA - IUFAO & Unuguay \\
\hline U Yale -JUFRO & USA \\
\hline USDAFS - IUFRO & USA \\
\hline ULA & Vervezuela \\
\hline
\end{tabular}

Chile

Chile

Argentina

Argentina

Argentina

Arasi:

Bras:

Chise

Chive

Colomba

Costa Rica

Costa Rica

Cuba

Ecuador

España

Espana

Fintandia

ndonesia

talia

Méxion

Mexico

Portaga

Unuguay

USA

Venezueita

Diraceion

Instituto Foresta|

Huerfanos 554 Casilta 3085 - Santago, Chle

Fono 5326990720 Fax 562.6381286

Correo electronico sbamosiginfor.gob. ol 


\title{
ANTECEDENTES PARA EL USO DEL MONTE BAJO DE Eucalyptus globulus EN CHILE'
}

\author{
Juan Carlos Pinilla S, Maria Paz Molina B., Mauricio Aguilera (1)
}

\section{RESUMEN}

El establecimiento de Eucalyotus globulus para obtener adecuadas productividades requiere de altos costos de establecimiento, siendo una demanda constante por parle de empresas y propietarios forestales las altematives tecnolćgicas para aumentar la rentabilidad de sus plantaciones y acceder a mercados en forma mas eticiente.

Una de las opciones es el manejo de la retoniacion del bosque de Eucalyptus grobuhus luego de una cosecha (Manejo del Monte Bajo). Esta opción puede significar menores plazos de rotación y una disminución de los costos de establecimiento inicial. Segùn la información bibliografica, el monte bajo presenta un crecimiento y rendimiento a lo mencs igual que el bosque original, soportando hasta 3 rotaciones antes de reemplazar la cepa onginal. Esta opción de manejo permitiria a los productores nacionales afrecer una producción de trozas pulpables de constante demanda, aumentando la rentabilidad del negocip asociado o permitiendo mejores condiciones de escenarios para su comercializacion, La decisicn de usar este tipo de manejo o continuar con una nueva plantacion requiere de precisar y validar los supuestos de costos, precios, rendimientos y tipos de productos a obtener. Evaluar estos factores en el pais requiere adomás, de adaptar y generar información o herramientas que puedan facilitar la terna de decisión por parte del silvicultor para distintas situaciones de crecimiento del monte bajo de $E$, giobuifus en Chile.

Se presenta los resultados a la fecha obtenidos por el Instituto Forestal en relación con los antecedentes de crecimiento e información acerca del manejo de monte bajo y de diversos factores productivos de este tipo de manejo forestal.

Palabras clave: Eucalyptus. globulus, retoños, manejo, crecimiento 


\section{SUMMARY}

An appropriato productivity in Eucalyptus globulus plantations requires high establishment costs and forests enterprises and land owners are always looking for better fechnologcal altematives to increase the planted forests profitability as well to access the markets in a more efficient way.

Ore of the options to reduce establishment costs and may be reduce the rotation period as well is the managoment in coppice after the first tum. Bibliography on the matter affirm that the coppice with the species can grow and yield at least equal than the original stand, allowing up to three turns before replacing the stems. The coppice alternative could improve the possitilities of the plantation owners to produce round wood for pulp under a better scenario regarding to profitability and markets. Decision make to use the coppice or establish a new plantation depands on appropriate information on costs, prices, yieids and protucts to obtain, so good tools to analyze these subjects, under different growing Eucsiyplus grobuies conditions in Chile, are needed.

Results on growth, coppice management and other productive factors obtained up to day by the Forest Institude are presented.

Key words: Eucalyptus, giobutus, growith, Doppice, management.

\footnotetext{
Deaimanto esberase en al mares del prevecto FONDEF D0211117 incraneanto des Negotio Forestal a Travks de

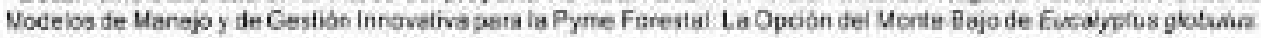

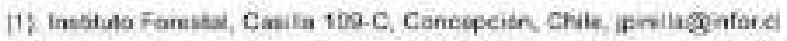




\section{INTRODUCCION}

\section{Antecedentes Generales Manejo Forestal de Eucalyptus giobulus}

Eucalyptus globulus fue introducido a Chile durante ei siglo 19 y actualmente existen en el pais unas 360 mil hectareas de plantaciones. La mayor superficie plantada se encuentra distribuida entre la V y $\times$ Regiones y su principal destino es la producción de celulose. La especie esta presente bajo las mas variadas condiciones de sitio. lo cual cemuestra su considerabie plasticidad ecolidgica.

El potencial de crecimiento demostrado por la especie $(20$ a $40 \mathrm{~m} / \mathrm{ha} / \mathrm{anfo})$ ha motivado atas tasas de forestación, lo que asociado a atractivos precios de la celulosa, ha generado una importante industria y mercado a nivel nacional. En esie esquema, el manejo lorestal se orienta a cosechar las plantaciones en su periodo de crecimiento máximo, evitando que el rodal entre en la fase de crecimiento moderado, La edad optima de corta es más tomprana cuanto mejor sea of terrono.

Es asi que buscando el máximo beneficio economico, se debe pensar además del producto a obtener, en el valor del dinero. considerando que este valor decrece con el tiempo si no se le hace producir. Desde el punto de vista de maxima produccion y del financiero, las edades optimas de corta en Chile para $E$ giobulus destinado a la producción de pulpa, se situan entre los 12 a 15 años. La edad de cosecha no se puede reducir en demasia en situaciones de monte alto, dado que los costos de cosecha y establecimiento llegan a ser altos si la cantidad de madera por hectárea desciende (plantaciones muy jövenes o irregulares en densidad).

Una de las caracteristicas de esla especie es su alta capacidad de retohlación, lo que se transforma en una ventaja al momento de decidir si optar por una nueva plantación o bien manejar los retoños que se generan a partir de los rodales cosechados (Manejo del Monte Bajol.

Esta opción de regeneración que presenta la especie y principaimente su bajo costo de establecimiento y rápiodo crecimento inicial, son factores importantes en su aplicaciòn para obtener productos de valor en rotacion mas conta ( 8 a 10 . versus 10 a 15 anos en la silvicultura tradicional), accediendo así a nuevos escerarios econdmicos y de mercados (Pinilla, 2005a).

Sin embargo, la decisićn de continuar con el esquema de monte ato o elegir el camino de regeneración de monte bajo no es fácil. Se debe considerar el electo del metodo de regeneración en los costos de establecimiento, costos de cosecha-transporte, rendimientos volumetricos y tipos de productos a obtener. Evaluar estos factores requiere ademas, de adaptar y generar información o herramientas que puedan facilitar la toma de decisión por parte del silvicultor. 


\section{El Monte Bajo como Herramienta de Gestión y Manejo}

El melodo de monte bajo se recomienda para obtener productos que puedan producirse en rotaciones cortas, como es el caso de la pulpa, postes o biomasa para dendroenergia. En el caso de E. glabulus puede obternerse sucesivos aprovecharmientos de un miemo tocón o cepa. Un adecuado tratsmiento de los trotes contribuye a la obsención de las siguientes cosechas. Los brotes despues del primer alo de la corta crecen con un gran vigor inicial debido a que estàn aprowechando las substancias de reserva acumuladas en las raices y que el arbol va a usar para rehacer lo antes posible la parte aèrea perdida. La producción en volumen de la segunda brotación suele ser superioc a la primera, mientras que la tercera corta parece igualar a la primera.

Se ha mencionado que a partir de la segunda corta es dificil que los brotes puedan superar en productión de madera a una nueva plantación (Andrade et al.., 1997; Ayling y Martins, 1981; Camargo et at., 1997. Gonzalez et at., 1997). Por lo general solo en lugares de gran calidad de sitio y una buena plantación y mantenimiento, sa compensaria aprovechar una cuarta corta?.

Los principales factores que inciden en la productividad de las cepas o tocanes se ha determinado que corresponden a

- Origen de los rebrotes

- Selección y manejo de las reloños

- Epoca de corta (cosecha)

- Método de volteo y tipo de corte

- Altura de corte del tocón

- Diametro y edad cel tocón

- Oportunidad del clareo

- Método de ejecución de clareos

- Númiero de retonos por tocón

- Cantidad de los cicios de corta

- Mortalidad do tocones

Los aspectos económicos asociados a los costos del monte bajo, asi como a los ingresos esperados, han sido materia de recientes estudios, y las empresas han manifestado interes por que se precise la información. De esto dependerán los esquemas de manejo de plantaciones y se podrá indicar en que condiciones o sobre que niveles minimos de productividad resulta conveniente incurrir en los gastos de una nueva plantación y en que condiciones resultaria recomendable regenerarta a partir de rebrotes.

Paralelamente y cen el objetivo de asegurar las maximas rentabilidades del negocio propuesto, se ha investigado en aspectos referidos a las caracteristicas de la madera proveniente de la retonación (densidad, aptitud pulpable) y el efecto de la fertilización score al crecimiento y rendimiento del monte bajo de eucalipto, factores determinantes en el uso de ios futuros productos a obtener y sus posibilidades de transacción en los mercados.

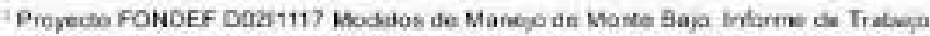




\section{Diferencias entre los Métodos de Monte Alto y Monte Bajo}

Las principales diferencias entre el esquema de manejo de monte allo (semilas y plantación) y el esquema de monte bajo (rebrotes) se pueden clividir en los siguientes aspectos:

- Costos de establecimiento: Dertro de los costos totales de producción de matera prima pulpable, los costos de establecimiento representan aprcximadamente un $45 \%$ del folal, por lo que cualquier aumento o disminucion de elos estara afectando directamente la capacidad competitiva del producto en un mercado tan exigente y dinámico como lo es el mercado de la pulpa. Una importante reducción de los costos de establecimiento se logra debido a un menor número de actividades e insumos requeridos para establecer la nueva plantación, actividades como preparación de suelo, plantación y control de tocones no se realizan en la regeneración por monte bajo. Las valores señalan valores de 700 US5/ha para el caso de una plantación versus 350 USSha para el caso del manejo del monte bajo. ${ }^{2}$

- Crecimiento: Para iguales condiciones de sitio, los rebrotes originados de las cepas crecen inicalmente más rápidamente que las plántulas provenientes de semilla. Algunos autores sostienen que esta ventaja no se mantiene en forma permanente sino que hay un momento en que la plantación supera al monte bajo: mientras mas antigua es la cepa, más temprano es superado. Este puno es muy importante, ya que conociendo el crecimiento del bosque se podrá determinar el mejor momento de la cosecha lo que finalmente definirá la rentabilidad del negocio forestal.

- Obtención de productos intermedios: La implementacion del método de regeneracićn de monte bajo requiere de la realización de clareos para homogeneizar el producto final o biomasa, extrayendo rebrotes de maners de llegar a 1 o 2 por tocón, dependiencto del tamafio de éstos, para asi concentrar el volumen. La ejecución de los clarecs genara productos de pequeños diámetros los que pueden ser utilizados como polines o biomasa también, generando ingresos que permitirian financiar estas intervenciones.

- Periodo de rotación: Las rotaciones en el pa's para bosques de Eircalyptus giabulus cuyo crigen corresponde a semilla es de 10 a 14 años. Para plantaciones originadas de monte bajo las rolacones se estiman serian mas cortas, no más de 8 a 10 años, debido a su rapido crecimiento inicial, la que permite obvener un fetorno de la inversión a un menor plazo, sin un carrbio significativo en las propiedades pulpables con una menor edad.

\section{Situación en Chile en Relación al Manejo del Monte Bajo de E. globukus}

Se ha destacado la excelente capacidad de retonlación de E. gobufus, reflejacis en el porcentaje de retoríos por tcoón que se producen y las dimensiones de estos. En Chile. sólo existia informacion proveniente de Prado y Bamos (1989) y akunos autores para casos especificcs (Ribalta, 1983; Peñaloza, 1985; Toral, 1988; Prado et al., 1990; Venegas y Bonnefoy, 1999), por lo que era necesario obterver y validar los antecedentes orientados al manejo del monte bajo y 
otros aspectos de su cultivo. Esta información ha sido puesta a disposición de los usuarios a traves del proyecto de monte bajo financado por FONDEF.

Estos ensayos señalaban que basta con dejar uno o dos retoños por tocón para obsener la maxima ocupacion de sitio y rendimiento volumetrico, La ventaja en este ultimo se manifiesta en obtener diámetros superiores y un menor número de árboles por hectárea lo que influye a su vez en los costos y eficiencia de la cosecha final (Prado et al, 1990; Toral, 1988, Pinilla, 2005b).

Los medianos y pequeños propietanios y las empresas, demandan información precisa y resultados de rentabilidad. Existen antecedentes de estudios puntuales sin analsis final o proyección en el tiempo, 0 con una valídación o extrapolación de sus resulados, pero se requiere dar respuestas validas al tema del manejo y caraclerización de los productos generados con el monte bajo.

En Chile, el programa silvicola de aljunas empresas se está orientando a manejar un gran porcentaje de la superfice cosechada a traves de monte bajo y el resto de la superficie a traves de una nueva plantacion de Eucalyprus gíabulus. Las cifras que se mencionan en este sertido seflatan valores de un 50 a $95 \%$ de la superficie bajo manejo de monte bajo.

Una nueva plantación se establece en esle marco en situaciones de canchas de madereo, caminos de temporade, sectores descubiertos, áreas de baja retoñación, reemplazo de bosques de mal desarrollo y reemplazo por malerial genético mejorado.

Hasta al momento la investigación de INFOR concluye que existe una diferencia entre las asintolas de crecimiento para monte alio y monte bajo. a través de la comparación del crecimiento de la regeneración con el historial del rodal que le dio origen, pudiendo comparar crecimientes y rendimientos?

La investigación hasta ahora sehlala que el monte bajo presenta un mayor crecimiento en comparación al monte alto hasla una edad de 8 a 10 años, luego de lo cual, el monte alto presentaria un mayor crecimiento. Este antecedente es importante ya que la mayor renabilidad del monte bajo puede permitir mantener rodales hasta los 10 anos, en comparación a bosques de la misma edad provenientes de semillas.

So ratifica los interesantes rendimientos obtenidos a temprana edad y la validez económica de la propuesta tecnológica, sustentada en las características del mercado, precios de productos, estructuras de costos, escenarios actuales y futuros y tendencias del mercado Se requiere de nuevas investigaciones para escalar las herramientas de gestión y para determinar, por ejemplo, si este tipo de manejo es utilizable en forma rentable y técnica para la generacion de biomasa dendroenergética.

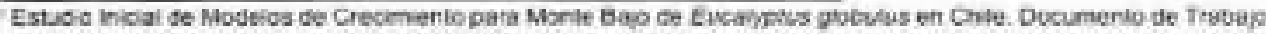

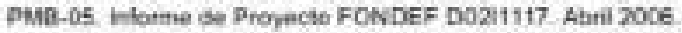


A continuación se presenta los resultados disponibles en relación ocn el crecimiento del monte bajo de $E$. globulus en Chile.

\section{OBJETINOS}

Generar y asociar información económica con la definición y proposición de la técnica saivicola del monte bajo en plantaciones de Eucalyptus giobulus, para contribuir a incrementar la renta de la PYME Forestal y propietarios particulares

\section{MATERLAL Y METODO}

La metodologia del estudio contempla et levantamento ce informacion sobre fodales manejados como monte bajo y estudios de productividad, sistematización y difusión de información reievanie, estudios de rentabilidad, caracterización tecnológca de la madera y un Modelo Sivicola y de gestion para monte bajo de E gíbulus.

\section{RESULTADOS}

\section{Caracterización Pulpable de la Madera de Monte Bajo}

Un punto de interés en el propecto se refiere a evaluar la aptitud pulpable del retoho de E globulus. La bibliografia consultada menciona la alta productividad del monte bajo, pero no sefiala la calidad de la pulpa posible de obtener a partir de ella. Por ello, se realizd un estudio acerca de las propiedades pulpables de la madera proveniente del monte bajo de eucalipto, a fin de compararlas con las caracteristicas pulpables de la madera de monte aito en edades de cosecha.

Los resultados señalan que se confirma el efecto de la edad sobre las caracteristicas de la madera, no existiendo dferencias con los valores de árboles de monte alto a las mismas edades. Los rangos de los valores de resistencia mecanica, obtenidos, abarcan valores correspondientes a trabajos con muestras de la VIII Región en edades de cosecha."

\section{Funcionalidad del Modelo de Volumen de Árbol Individual para Monte Bajo}

A partir de la información recopilada desde las unidades experimentales dei proyecto, se realizo un estudio para la determinación de volümenes de arboles individuales. Con esta actividad se aralicó si los modelos ce Volumen de Árbol individual para E. globulus existentes son utilizables en el monte bajo, luego de lo cual se podra decidir acerca de la necesidad de conatruir modelos independientes para esta variable.

Se realiz $\delta$ un muestreo cosechando 77 arboles de monte bajo en distintos rodales distribuidos en la V. VII VIII y X Regiones. Estos fueron medidos en secciones y se les calculo su volumen total hasta un diametro minimo de 5 centimetros. Luego se calculó sus volùmenes a través de las funciones desarrolladas previamente por INFOR, las que utilizan 
como variabies de entrada el DAP y la altura tolal del arbol. El modelo para estimar el volumen de arbol individuat $y$ analizat su funcionalidad corresponde al desarrollado por INFOR (Bahamondez et al, 1995), el cual corresponde a:

$$
\mathrm{Vh}=-0,00198+0,000026756 \mathrm{D}^{2} \mathrm{H}
$$

Donde:

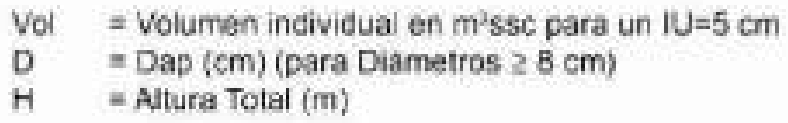

El estudiós concluye que el modelo existente de volumen de árbal individual puede ser aplicado en el caso del monte bajo de $E$ globulus

\section{Ensayo de Fertilización}

La investigacion en eucalipto ha permitido instalar durante el aho 2005, 6 unidades para estudiar el efecto de la fertilizacion sobre el crecimiento del monte bajo de $E$. globuhis. Detalle de los ensayos en el Cuadro $N^{5} 1$.

\section{Cuadiro $N^{\circ} 1$ \\ ENSAYOS DE FERTILIZACION}

\begin{tabular}{|c|c|c|}
\hline Ensayo & Sector & Rogion \\
\hline 1 & Lojea & V \\
\hline 2 & Longobomo & V \\
\hline 3 & Constitucion & VII \\
\hline 4 & San Javies & VII \\
\hline 5 & Pidra & IX \\
\hline 6 & Puerto Mont & $X$ \\
\hline
\end{tabular}

En este tipo de ensayo se intenta verificar el efecto de la fertilizacion tradicional sobre el rendimiento del monte bajo. La bibiografia reporta que el monte bajo necesitaria de una fertilización de apoyo, ya que el rodal orignal se supone utilizo los nutrientes presentes en el suelo, no siendo estos estudios concluyentes a este respecto. Es asi como Assis et af (1985) indican que la productividad de tocones es función de la calidad y cantidad de nutrientes disponibles para la planta. Estudios donde se aplico N y P concluyeron que no existieron diferencias significativas en diametro y en altura entre tratamientos, peco si superaron al testigo. Otros autores recomiendan fertilizar ya que en un principio el sistema radicular parciaimeinte establecido provee de nutrientes a través de sus resorvas orgánicas, pero con las altas tasas de crecimiento, estas decrecen drasticamente (Reis y Reis, 1997). Las operaciones de fertilización en áreas con serias restricciones hicricas y baja densidades de àrboles no seria recomendada, pero en un ärea con buen nivel hidrico, buena scorevivencia

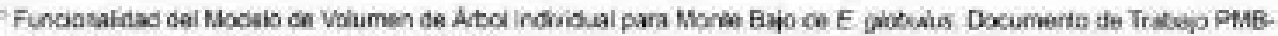
OA. Proyedo FONbEF Dozistil; Jurio 2000. 
y solo bajo nivel de fertilidad, la fertilización seria altamente conveniente (Stape, 1997). Se recomienda la fertilizacibn con nitrogeno $(\mathrm{N})$ y fosforo $(\mathrm{P})$, incluso antes de iniciada la brotación. ya que las raices no entregan estos elementos. En el caso del potasio (K), el sistema radicular entrega sólo este elemento para et crecimiento de brotes, en la medida que el sistema radicular recupera las raices fnas y medias este elemento es proporcionado por el suclo (Barros of al, 1997).

En los tratamientos se varió el aporte de nitrógeno, manteniendo constante el fósforo y el potasio. Los elementos fuentes de cada nutriente correspondieron a Urea (Nitrógeno). Superfosfato Triple (Fóforo) y Salitre Potasico (Potasio). A continuacion se presentan las dosis utilizactas en el ensayo.

\section{Cuadro $\mathrm{N}^{\circ} 2$}

DOSIS UTILIZADAS EN CADA ENSAYO

\begin{tabular}{|c|c|c|c|}
\hline Tratamiente & Eamanto & Dosis ofpt & Kha Elamenta \\
\hline 1 & Teshos & Tentip & Textgy: \\
\hline \multirow{3}{*}{2} & N & $\omega$ & 100 \\
\hline & $P$ & 120 & 200 \\
\hline & $x$ & 30 & 30 \\
\hline \multirow{3}{*}{3} & N & 120 & 200 \\
\hline & $r$ & 120 & 200 \\
\hline & $x$ & 30 & so \\
\hline \multirow{3}{*}{4} & N & $\infty 0$ & 158 \\
\hline & 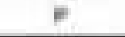 & 120 & 205 \\
\hline & 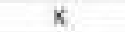 & 30 & 50 \\
\hline
\end{tabular}

Las conclusiones iniciales señalan que luego de un año de aplicado el fertilizante. aún no se detectan diferencias significativas entre los tratamienlos y que hasta la fecha todos los mejores tratamientos han generado un mayor volumen total que el tratamiento sin fertilizar (Figura $\mathrm{N}^{0}$ 1), siendo necesario incluir en los futuros análisis el costo de ta fertilización y su relación con el mayor crecimiento posible de obtener.

La estrategia a ser utilizada sera definida a traves de la evaluacion de los costos de la aplicación de fertilizantes y ce los resultados su aplicación en términos de incremento en rendimiento. 


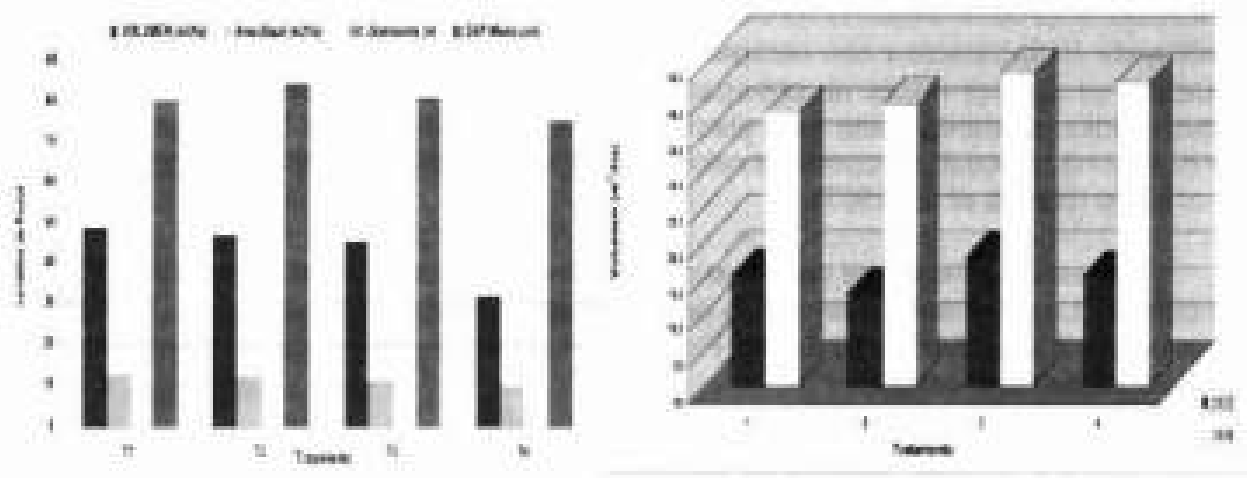

Figura $N^{0} 1$

SITUACION INICIAL DE LOS TRATAMIENTOS EN EL ENSAYO DE FERTILIZACION Y EVALUACION DEL VOLUMEN SEGUN TRATAMIENTOS ENSAYO DE FERTILIZACION, SECTOR LONGOTOMA

\section{Crecimiento y Rendimiento}

\section{- Intormación Utilizada}

Los datos provienen de parcelas permanentes instaladas en rodales de monte bujo. El número total de parcelas permanentes utilizadas en el analisis asciende a 38 con un total de 79 mediciones. Cada una de las parcelas tiene una superficie de $500 \mathrm{~m}^{2}$, con una forma rectangular $(20 \times 25 \mathrm{~m})$. En cada unidad se han medido parametros del ábol tales comb el CAP y altura.

En términos de distribución de edades, practicamente toda la intormación se concentra entre los 3 y 12 anios de edad (Figura $N^{\circ}$ 2). Este rango es un factor que necesariamente afecta las estimaciones de las modelos que se obtenga.

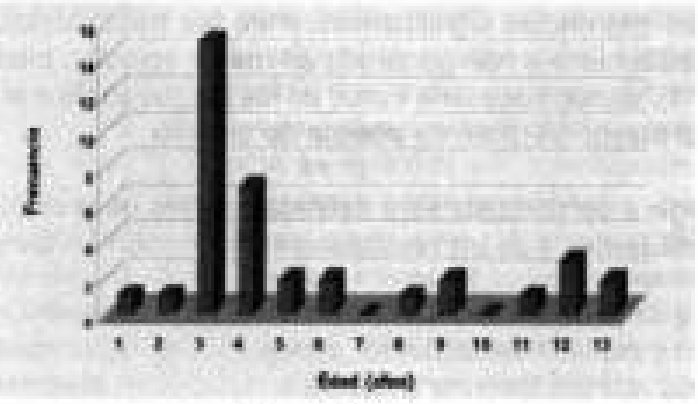

Figura $\mathrm{N}^{\circ} 2$

DISTRIEUCION DE FRECUENCIAS DE LA EDAD DE LAS PARCELAS PERMANENTES DEL PROYECTO 


\section{- Descripción de Rodales de Monte Bajo en Chile}

Para describir la siluación de los rodales de monte bajo que se esta ulilizando en la investigación, se presenta la Figura $\mathrm{N}^{\circ} 3$ con las varlables de rodal en monte bajo (MB) obtenidas, entre elas edad y area basal; edad y altura domnante; area basal y volumen; $y$ edad y volumen. En algunos gráficos aparecen además, comocomparación, datos de bosques de E. globulus originados a partir de semilla (Monte Ato MA).

De acuerdo con la información obtenida desde las distintas unidades, E. giobulus bajo el esquema de monte bajo presenta una alta supervivencia (85-90\%) y una asintota en altura de $28 \mathrm{~m}$ a los 9 ah̆os de edad. En términos de la producción, los resultados obtenidos de diagramas permanentes indican aumentos arvales en volumen en el promedio de $20 \mathrm{~m}^{2}$ ? havaño, con valores máximos de $35 \mathrm{~m}$ 3hàaño.

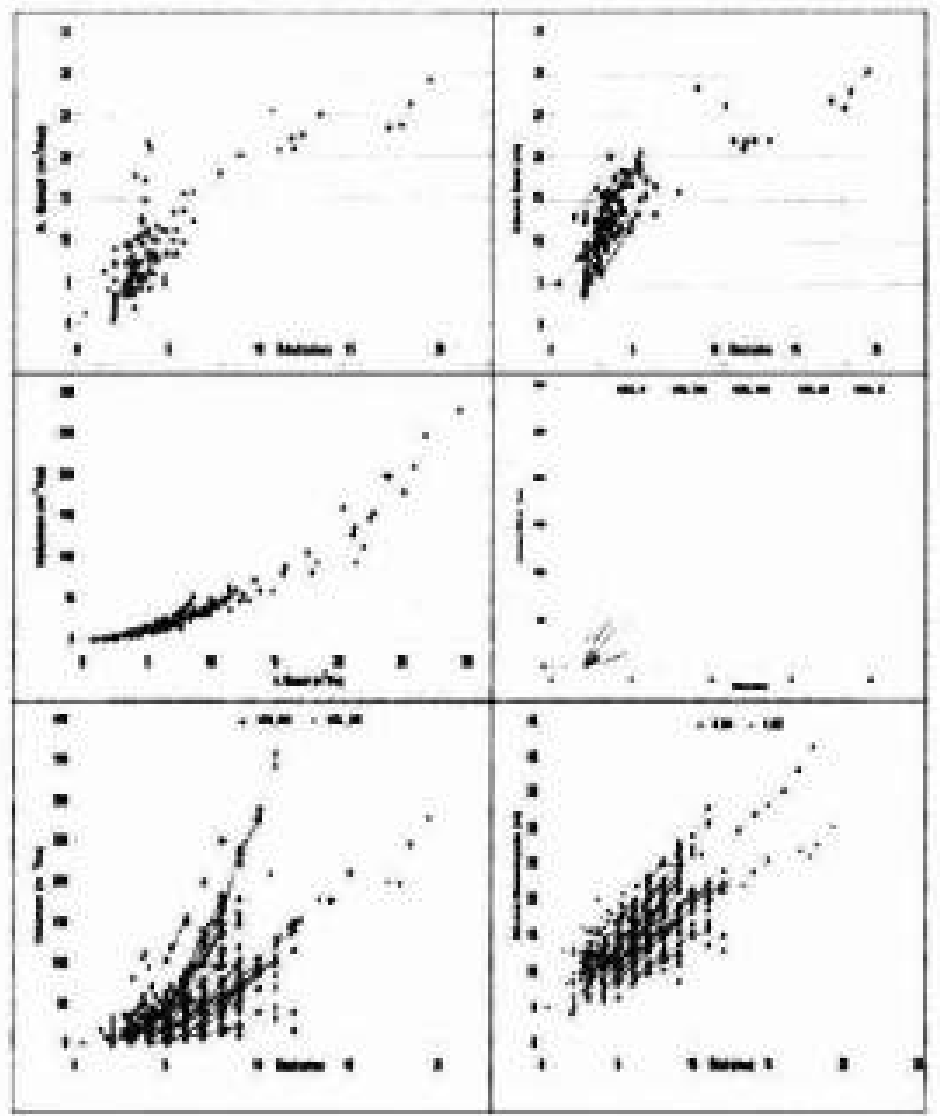

Flgura $\mathrm{N}^{2} 3$

VARUABLES DE RODAL EN MONTE BAJO (MB); EDAD Y AREA BASAL; EDAD Y ALTURA DOMINANTE; AREA BASAL Y YOLUMEN; EDAD Y VOLUMEN. 
De las figuras anteriores se destaca el acelerado crecimiento inicial registrado en los rodales de monte bajo, junto con rendimientos volumétricos semejantes a los obtenidos para el monte alto de $E$ guobuius.

En la Figura $\mathrm{N}^{*} 4$ se presenta las series de altura dominante obtenidas desde las parcelas permanentes de monte bajo, junto con proyeccicnes de Sitio cbtenidas desde anteriores trabajos de INFOR con plantaciones de monte alto. De la figura se concluye que los rodales de monte bajoestarian presentando un crecimiento al menos similar a los obtenidos desde rodales de monte alto.

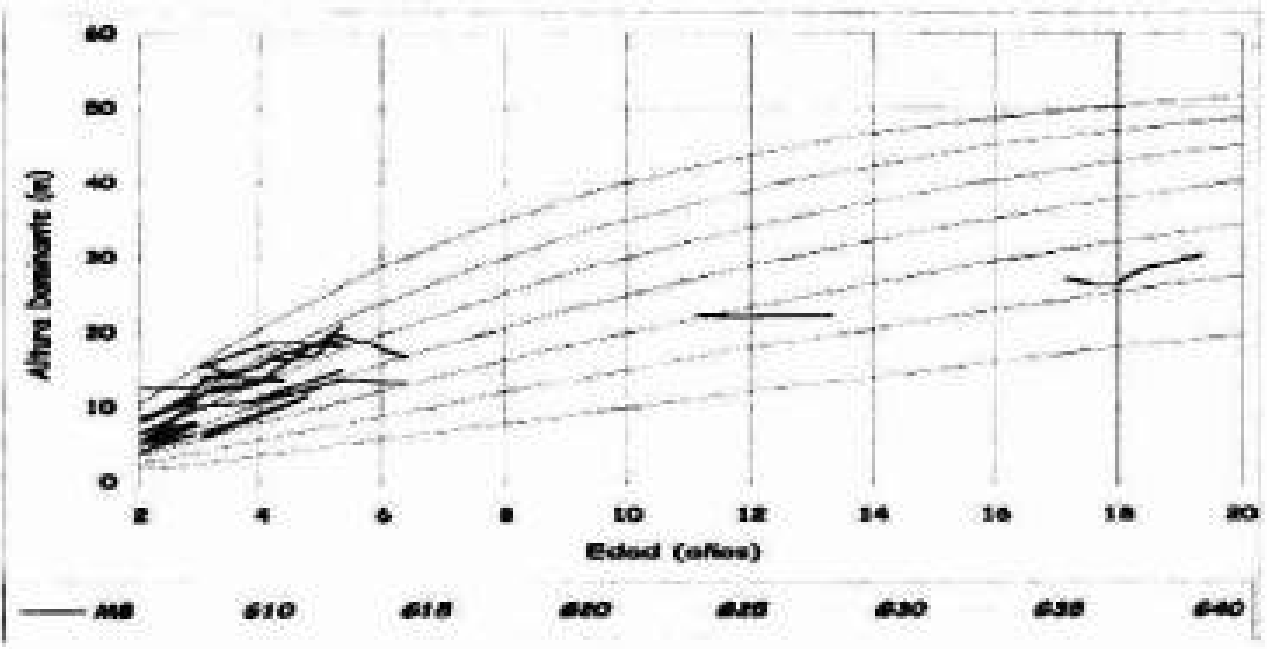

\section{Figura $N^{2} 4$}

SERIES DE MEDICIONES EN ALTURA DOMINANTE OBTENIDAS EN PARCELAS PERMANENTES DE MONTE BAJO Y SU COMPARACION CON CURVAS DE INDICE DE SITIO PARA PLANTACIONES DE NONTE ALTO DE E. globulus

Los resultados principales de la investigación apunten a obtener antecedentes de crecimiento y los modelos de apoyo (sitio, volumen, área basal) para este tipo de bosque. Su uso permitirá establecer una linea de investigación con las plantaciones de monte bajo de corta rotacion de $E$. giabulus an Chile.

\section{- Modelos de Crecimiento para Monte Bajo}

El estudio intenta validar o generar modelos de crecimiento y rendimiento para el monte bajo de $E$, giabulus. Entre los principales modelos se cuentan: 
- Crecimiento en Altura

- Mortalidad natural

- Modelo de crecimiento y rendimiento para Area Basal

A. Modelo de área basal inicial ( $G_{\text {, }}$ )

B. Modelo de crecimiento de Area basal $\left(G_{e}\right)$

- Modelo de prediccion para Volumen Total

En eate proceso inicialmente se aplico los modelos desarrollados para mome alto, pero los resultados no fueron satisfactorios.

Por lo anterior, se reajusto los coeficientes de los modelos para las parcelas de monte bajo. Una vez reajustados los modelos, ccn la información obtenida desde los rodales de monte bajo, se obtuvo una mejora significativa en los resultados de las estimaciones, en especial en el caso del volumen (Figura $\mathrm{N}^{\circ} 5$ ), la altura dominante y la mortalidad natural.

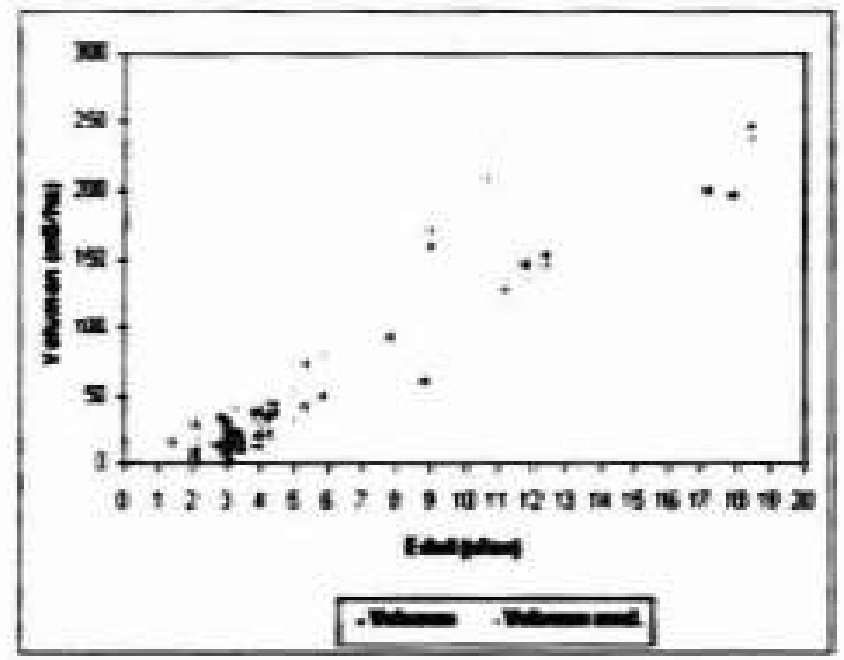

Figura $N^{2} 5$

ESTIMACIONES PUNTUALES Y SIMULACION PARA RENDIMIENTO EN VOLUMEN MONTE BANO (-)

El andisis preliminar de los resultados senala que existe diferencia entre las asintotas para monte alto y monte bajo, donde la asintota para monte bajo es inferior. El crecimiento en altura para monte bajo es mayor en un principio, pero luego es alcanzado por el crecimiento de monte alto que tiene una proyección mayor en altura (Figura $\mathrm{N}^{\circ} 6$ ). 


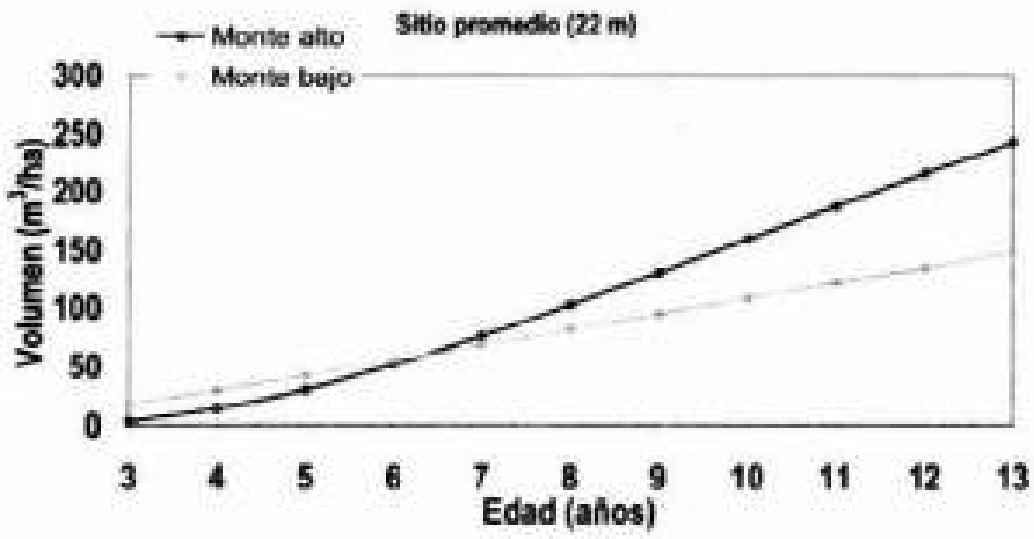

\section{Figura $N^{*} 5$ \\ COMPARACION DEL CRECIMENTO DEL MONTE ALTO Y MONTE BAJO PARA UN SITIO PROMEDIO}

En este mismo análiss es necesario incluir el estudio del punto de quiebre en relación con la rentabilidad asociada a este tipo de manejo en relación con la entregada por el monte alto. En este anălisis se debe considerar los costos de establecimiento y manejo, rendimientos volumetricos, rotaciones y precio del producto.

\section{- Evaluación de la Economía de la Producción}

Durante el desarrollo de la inwestigación continuamente se realiza una evaluación econdmica, analizando la validez de los supuestos empleados, enfrentando y cotejando la mantención de escenarios, las proyecciones de rendimiento y fundamentalmente, las lendencias de costos y precios que inciden en la validez económica de la propuesta.

Este estudio implica el analisis de los costos involucrados en el proceso. de los ingresos (estudio de los precios segùn distintas condiciones), indicadores de rentabilidad, etc. Tambièn el analisis se basa en supuestos ascciados a rendimientos, condiciones de sitio, densidad, etc. Para ello se recopila información de onstos asociados a las faenas de manejo del monte bajo, costos de opciones silvicolas, tasas de interes, precos y cosios de la produccion de productos alternathos o del monte alto.

El análisis de escenarios no es concluyente, dado que efectivamente los supuestos son los que deben ser validados a través de la investigación, lo que permitirá acceder a informacion importante al momento de la toma de decisiones.

Reunida toda la información se procede a ingresar los datos a planillas evaluadoras generades por el proyecto (Figura $N^{\circ} 7$ ), en donde bajo ciferentes escenerios se obtiene distintos indicadores de la rentabilidad del monte bajo de E glabulus Entre los más importantes se incluye los valores del Valor Presente Neto (VPN) y de la Tasa Interna de Retorno (TIRY. 

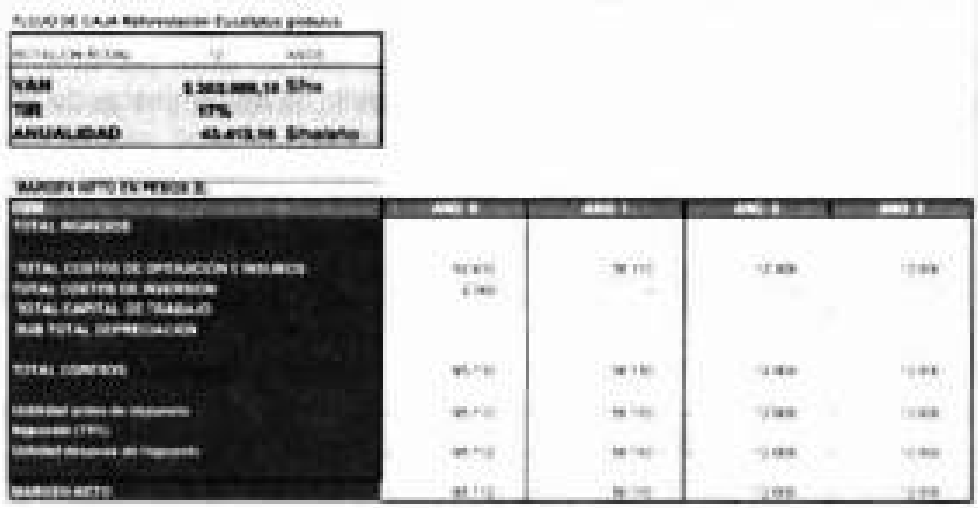

telia te consa

enchersen

Figura $N^{2} 7$

PLANILLA DE RENTABILIDAD PARA MONTE BAJO DE Eucalyptus globulus DESARROLLADA POR INFOR

\section{- Herramienta de Gestion para Productores}

Los modelos desarrollados por INFOR pare el ceso del monte bayo han sido incluidos en una planilis en formato Excel, en la cual se puede leer los rendimientos en volumen, densidad, altura $y$ área basal a una edad determinaca

Este tipo de herramienta es de interes para productores, investigadores e interesados en el manejo del monte bajo de E. giobulus. En la actuatidad, no existe un instrumento de gestión que pueda ser utilizada en el monte bajo y la inclusión de la variable edad permite generar un modelo de tipo dinamico actuaimente inexistente.

Este modelo está siendo evaluado constantemente, demostranco hasta ei momento adecuadas capacidades estimatorias. Sin embargo, los modeles de monte bajo están atectados por ta edad de la información con que se cuenta. por que es importante manejartos con cautala, considerando que solo son un primer paso. Su mejora soblo podrá ser posible cuanoo se cuente con mayor número de mediciones y con una mayor densidad de estas. para el rango de edades qua va de los 6 a 12 ahos de edad.

\footnotetext{
"Proyecio Fonger Dozi1117 Node os de Manejo de Mone Bojo. Documanio de Tratajo PMB-os Analisis de Whencis Econdmica, Novierebre zooti
} 


\section{CONCLUSIONES}

Se destaca el interesanie crecimierto registrado en Chile por el monte bajo de Eucaíypius globulus y la neces dad del desarrollo de herramientas de apoyo para el manejo eficiente del monte bajo con esta especio.

Existe diferencia entre las asintotas para monte alto y monte bajo, donde la asintota para monte bajo es inferior El crecimiento en altura para monte bajo es mayor en un principio, pero luego es alcanzado por el crecimiento de monte alo que tiene una proyeccion mayox en altura.

Luego de un ańo de aplicado el fertilizante en los ensayos, aùn no se detectan diferencias significativas, pero los mejores tratemientos han generado un mayor volumen total que el tratemiento sin fertilzar, siendo necesario incluir en los futuros anallisis el costo de la fertilización y su relación con el mayor crecimento posible de obtener.

Los modelos de monte bajo están fuerterrente efectados por la adad de la información con que se cuenta

Una vez reajustados ins modelas con la informacicn obxenida desde los rodales de monte bajo se obtuvo una mejora sigriflcativa en los resultados de las estimaciones, en especial en ef caso de la alture dominante y mortalidod natural.

Estos modelas son un primer paso. Su mejora será posible cuando se cuente con mayor número de mediciones y con una mayor densidad de estas para el rango de edades que va de los 6 a 12 años de ectad.

Es necesario mantener las med ciones a fin de establocer al los resultados obtenidoc hasta ahora se mantienen o varian en ed timmpo.

\section{AGRADECIMIENTOS}

Los autores agradecen al personal de las empresas y propietarios particulares participantes del estudio, sin lus cuales esta investigaciōn no se hubiera materializado.

\section{REFERENCIAS}

Andrade, H., Benedetti, V., Madaschi, J.y Eernardo, V., 199r. Aumeno da Piodubvidabs da Segunde

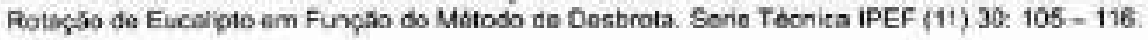

Assis, R.; Ferreira, M.; Morais, E.; Cameiro, C.; Dias, M.; De Morais, E., 1996. Eehaviour of Seil Moishure and Weter Slorege in Evcalyptus wophyle Pankatons at Dillerent Spacings Compsred wh the Cerrado Vegetation ar Bocaluva (MG) Ciencia E Agrcitecnotoga 22) 1k. $79-\infty 6$.

Ayling. RD.; Martins, PJ., 1931. The Growing of Elacalypts on Short Rotation in Brazil. Forestry Clronicle. $57(1) .9-16$. 
Bahamendez, C., Ferrando, M.; Martin, M. y Pinilla, J.C., 1995, Delermnaoún de Funóanes de Wot.umen y Razon de Wolumen para Eucalipto, Irsensto Forestal-Fondet, Documonco Proyecto Conicyt-Fondef 233. $18 \mathrm{p}$.

Barros, N., Teixeira, P. y Teixeira, J., 1997, Nutnçäo e. Produtividade de Povamentes de Eucalipto Manojacos por Talhadia. Serne Tecnice IPEF (11) 30. 79-8?

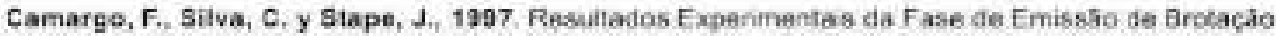
em Ecicalyprus Mancjado por Taltadia. Sarie Tecrica IPEF(11) 30 115-122.

Gonzalez-Rio, F- Castallanos, A.; Fornandez, O.; Astorga, R. y Gomez, C., 1997. El Cuttive del Eucalipto. Wanua Practico del Selircuitor. Celuloses de Asturias 5 . A. Prinopedo de Asturias. 95p. Matp?

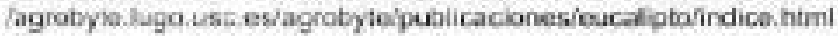

Peralaza H., M. 1985 Funciones de Volumen Cíbico para la Especie Eucabotus globurus Labil de Monte Baju, en la Región Netropoltana CONAF. Programa de Fomento y Desarrolo Forestal Región Medropolitana CONAF, Boletin Tecnico N*.25. Santiago, Chile, $74 \mathrm{p}$.

J.C. Pinilla S., 2005a. Antecadentes Canerales Acerca dal Manejo de Mante Bejo de Eucafyptus ghatuhia. INFOR, Perdoriado por FONDEF Concepcićn, Chibe, INFOR. 44p lus, tab.

Pinilta, S., J.C., 2005b. La Opodon del Monie Bajo para el Eucaíyptus giobulus. En Chila Forestal(313):2829

Prado, J.A. y Barros, S. (Ed.) 1989. Evcalyptus: Principios de Silviculura y Marnju. Irethuto Fonostai, Sentogo, Ohile.

Prado, J A: Banados, J.C.; Bello, A., 1990. The Coppicing Ablity of Sorre Speces of Eucroblus in Chie. Insteuto Forestal, Casdia 3065, Sanfiago, Chile. Ciencia e Investigación Forestal. 1990, 4: 2, 183-190,3 ref.

Reis, G. y Reis, M. 1997. Fssiokgia da Brotaçàs de Eucalipto com Enfase ras suas Relacoes Hidricas. Serie. Tecnica IPEF (11) 30 9-22

Ribalta S. E., 1983. Evaluación de is Producción y Producinidad del Monte Bajo de Eucalyotus giouulus [Lab.]. V Region. Tesis para optar al Grado de ingeniero Forestal. Universidad de Chive. Facultad de Cienoias Agrarias. Veterinarias y Forestales. Santiago, Chile. $124 \mathrm{p}$

5tape, J., 1997. Planejamento Glotal e Ncrmalizaço de Procedimentes Cperacionats da Talhadia Simples em Eucalyptus. Serie Tecnica PEF (11) 30:51-62.

Toral I. M., 1988. El Electo de Diversas Inlensidades de Clareo en et Cracimiento de Mente Bajo de Eucalyotus grobutus. En Aclas Simposio Manejo Sivicola del Genero Eucadyptus Wiña det Mar, Crile. 9-10 Jun, 1988, p9,310-333. INFOR-CORFO

Venegas, R. y Bonnefoy, P., 1999. Métado de Regerieración de Monte Bajo ert Eucalyprus sp. Xil siluctecrat Realidad y Potencial del Euxalipes en Chile. Concepeiton - Chile 


\title{
ANALISIS ECOMOMICO DE OPCIONES PRODUCTIVAS PARA PLANTACIONES DE Eucalyptus nitens EN EL SUR DE CHILE
}

\author{
Juan Carlos Valencia Baier (1) y Jorge Armando Cabrera Perramon (2)
}

\section{RESUMEN}

Invertir en establecer y manejar plantaciones de Eucaiyptus nitens para producir roilizos podados con alta proporción de madera libre de nudos para chapa o aserrio. conjuntamente con rollizos aserrables con nudo firme y madera pulpable, cada dia cobra mayor interes en procuctores e imversionistas forestales, frente a la opción necamerte pulpable; sin embargo, dado su relativo reciente desarrolio en Chile, son escasos las antecedentes aobre la rentabilided de esta altemativa, situacicn que este trabajo buaca mitiger mediante un analieis económico para la realidad productiva del sur del pais.

Con dicha finalidad, se desarrolló un modelo de actualzación de flujos de caja. con el cual se estimo y comparo la rentabilidad de invertir en plantar $E$. nitens considerando: a) un "Regimen Clear" o "Manejo de Alto Valor", con edad de rotación de 20 años, incluyendo tres podas y dos raleos comerciales; y b) la apción de producir sólo madera roliza pulpable. considerando para ello un tlujo de caja de dos rotaciones de monte alto sucesivas. de 10 anos cada una: forestación y reforestación. En ambos casos se estimo el Vaior Neto Preserte (VNP); el Ingreso Anual Equivalente (IAE) y la Tasa interna de Retorno (TIR) para dos condiciones de productividad de sitio: alta (IMA $45 \mathrm{~m}^{3} / \mathrm{ha}$-año; IS 33 ) y media (IMA $30 \mathrm{~m}$. Whasño: IS 26), representativas del rango de crecimiento observado en el sur de Chile

Además, se analizo la rentabilidad de la opción pulpable para dos rotaciones de monte alto de E. globurus, tambien bajo dos condiciones de sitio: 20 y $30 \mathrm{~m}^{3}$ haraño. representativas de una productividad media a alta para la especie.

Los resultados indican que al $8 \%$ de tasa de descuento $y$ en sitios de alta productividad, el VNP de la opción de alto valor de E. nitens se estima en 1.322 y 2.343 US $\$$ / ha, según se considere o no el costo del terreno, generando 1.226 US $\$$ i ha sobce la opcion de invertir en dos rotaciones pulpables con la misma especie. En un sitio de procuctividad media, el VNP de la opción de alto valo se estimo en 355 y 1,101 US $\$$ / ha. según se considere o no el costo del terreno, generando 792 US 5 i ha subre la opcian pulpable. En téminos relativos, la rentabilidad de la cpción de alto vaicr fluctuó entre 9,0 a $16,2 \%$ real anual según productividad do sitio $y$, si se considera o no el costo del terreno, rentabilidad que para la opción pulpable con $E$. nitens se estimó en el rango ce 6,1 a $15 \%$ real anual.

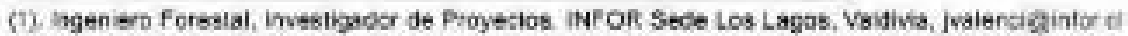

(2). Ma (E) Eescomia Agratia, Ingeniers Forestal, Dinectse de Propactos, INFOR Sede Las Lagas, Vaidisa jeatrerafinlord 
Se concluye que la opción de alto valor exhibe una alta rentabilitad, muy superior a la opoón pulpable, que de consclidarse los mercados para la madera de $E$. nitens, puede significar importantes retomos para pequerios y medianos propietarios forestales.

El analisis a nivel de rocal de la opción pulpable con E giobulus, determino altas rentabilidades en los sitios evaluados, concluyendo que no debieran primat razones económicas para cambuar el uso del suelo por $E$. nièns, oonde $E$ globulus logre crecer con un IMA sobre $20 \mathrm{~m}$ /ha-afho.

Palabras clave: Eucalyptus nitens; $E$. globulus: plantaciones: manejo: rentabilidad.

\section{SUMMARY}

Investing in establishing and managing plantations of Eucabyptus netens for solid wood products to produce pruned logs with hign peoportion of clear wood for appesrance veneer or sawn timber: sawlogs with knots for structural and industrial products and pulpwood, is an cption that each day takes more attention in forest producers and investors. set against the pulpwood plantation option, nevertheless, product of ther relative recent development. are scarce the antecedents about profitability, situation that this study mitigating with an analysis and comparison of the stand economy of both options, for the southern productive reaity of Chile.

It is developed a cash flow model for financial analysis wth which was calculated and compared the profitability of imvest in planting $E$, nibens considering a) "Clear Wood Regime' or "Higher Value Management", with a twenty year rotation, including three pruning and two commercial thinning; and b) the option of producing only pulpwood, considering for it a cash flow of two successive ten year rotation pulpwood each one. In both cases was calculated the Net Present Value (NPV). Annual Equivalent Return (AER) and internal Rate of Return (IRR), for two site productivity: high (MAl of $45 \mathrm{~m}+\mathrm{ha}$ / yr, SI 33) and medium (MAI of $30 \mathrm{~m}^{3}$ hha i yr. Si 26), representative of the rank of growth obsenved for the species in the South of Chile:

Additionally, was evaluated the profitability of puipwood opton for two rotations of $E$ globulus, considering an MAl in volume of 20 and $30 \mathrm{~m}^{\text {l/ }}$ ha $/ \mathrm{yt}$, representative of a mean to high site productivity for this speces.

For a discount rates of $8 \%$ and in a site with high productivity, the NPV of the Higher Value Management of $E$. nutens was calculated in 1.322 and 2.343 US \$ Tha, according to be considered or not the cost of the land, generating an increment in the NPV of 1.226 US $\$$ / ha set against the option of investing in two pulpwood rotations with the same species. In a site with medium productivity, the option of higher value generates a NPV of 355 and 1.101 US \$ Tha. considering or not the cost of the land, generating an increment in the NPV of 792 US S I ha set aganst the pulpwood plantation option, indicating the economic convenience of invest with objectives of solid wood products with higher value utilization. The IRR of the higher value management with $E$. mtens fluctuates among the 9,0 to $16,2 \%$ real annual 
according to sile productivity and if is considered or not the cost of the land, profitability that in the pulpwood option with $E$. nitens was carculated in 6,1 and $15 \%$

It is concluded that the option of higher value with $E$, nutens is an alternative with high profitability, much betser than the pulpwood plantation option. therefore. If a market for $E$. nitens sawlogs and veneer is consolidated, the higher valve plantaton option can produca important benefits for small and medium owners of the country

The high profitability of the puipwood piantation option with $E$. globuitus, permis to conclude that should not exist economic reasons for the land uses change with $E$ nitens where E. globulus can grow on $20 \mathrm{~m}^{3} / \mathrm{ha} / \mathrm{yr}$.

Key words: Eucalyptus nitens; $E$. globulus; plantations; clear wood regime; profiability 


\section{INTRODUCCION}

La superficie mundial de plantaciones de eucalipto se estima en 19,4 millones de nectareas (Baso 2004), onentadas principaimente a la producción de madera pulpable y combustble en rotaciones de 8 a 14 ahos; sin embargo, los ultimos 5 a 10 ahos, un porcentaje creciente de esta superficie ha ido cambiando su orientación productiva, para ser establecida, manejada y cosechada, por numerosas empresas, entre ellas algunas multinacionales, para producir madera rolliza libre de nudos y cefectos para aserrio y chaoas, aprovechando la oportunidad de mercado que determinan la restricción de oferta de maderas duras tropicales y el crecimiento proyectado de la demanda por productos de madera sólida de alto valor, en especial de las principales ecchomias como EEUU, Japon, China y la Unión Europea (Flynn, 2005). El progresoevidenciado los ultimos 5 anos en genésica, silvicultura, cosecha, tecricas de aserrio y secado de madera de eucalipto, ha fortalecido ef desarrollo de esta opcion, superando con ello numerosas barreras tecnologicas y. de paso, algunas concepciones arraigadas sobre una supueata mate reputación del genero para dichos usos.

De esta manera, además del mercado pulpable y. eventualmente, de la madera reconstituida o compuesta', Flynn (2005); Nolan et al, (2005): Montagu et al. (2003) y Shield, (2002), identifican tres sectores de mercado para rolizos de plantaciones de eucaliptos: a) paliets y embalajes; b) madera aserrada y chapas de uso estructural; y c) rollizos podados con alta proporción de madera libre de nudos y defectos para usos en los que predomina lo estetico. como chapas deccrativas y madera aserraca ciear, El primer mercado utiliza rollizos de baja calidad, sector en que los eucaliptos ya incursionan con éxito a nivel mundial, incluso en Chile con E. nitens: el segundo mercado, para uso estructural, requiere de rollicos de alta calidad con pocos nudos y defectos para alcanzar las exigencias regueridas por norma. Sin embargo, algunos autores estiman que los eucaliptos serian poco competitivos frente a la madera de coniferas, ontre elias Pinus radiata, que dominan este mercado (Montagj of al. 2003; Cabrera, 2003), no obstante, sl podrian tener oportunidades en aplicaciones en que la resistencia y tamaño sean importanies, o eventualmente como madera laminada para uso estuctural (Gaunt et at, 2003, Mckerzie et al. 2003; Montagu et al. 2003; Shieid, 2002), de hecho en Tasmenia, Australia, la emprese Forest Enterprise of Australa produce madera aserrada para uso estructural, denominada EOOAshB, oon plantaciones de E. nitons². El tercer sector, de ahto valor (appearance grade) para muebleria, pisos, molduras y chapas decorativas, se perfila como el mercado con las mejores oportunidades para madera de plantaciones de eucalipto y al que se apunta con E. nifens, caracterizado por ser un mercado estable y de altos precios, tradicionaimente satisfecho por maderas duras de especies tropicales, derta cue progresivamente comienza a ser más escasa. Flynn (2005) concluye que es inevitable que progrese el uso de alto valor de las plantaciones de eucalipto y emerja como un importante componente del negocio mundial de maderas del sigio 21, en usos y aplicaciones de la madera solida y en productos de ingenieria como el LVL. OSB y LSL (Laminatod Strand Lumber).

De hecho. en varios paises cperan empresas de diverso tamaño que manejan plantaciones y transforman madera de eucalipto para chapas y madera aserrada. En Brasi

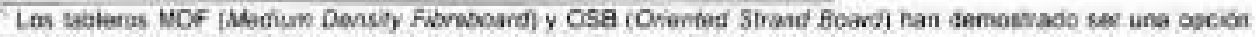
induslrai imeresante pars aigunos eucafolos. enve 6 kos $E$. wens.

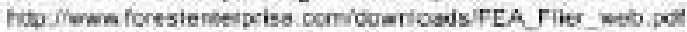


destacan Aracnuz. Klabin. CAF Santa Bärbara y Boise Cascade, en Argenlina Forestadora Tapebicua y MASISA; en Esparia el Grupo ENCE; en Uruguay Cohusa-Unufor, Euforest (ENCE) y Colonvade (jaint venture Wayerhauser/UBB); todas utilizando Eucalyptus grandis; en Sudatrica la empresa Mondi esta renovando sus instalaciones para procesar madera de sus piantaciones y en Australia las empresas Gunns Ltd, Forestry Tasmania y Forest Enterprise of Australla cultivan $e$ industrializan plantaciones de $E$. nitens.

Se suma la investigacion y desarrollo sobre cultivo y procesamiento de plantaciones de aucalipto para madera sólida, ejecutada por numerosos institutos y centros tecnológicos tales corto LATU en Uruguay. INTA en Argentina. EMBRAPA en Brasil, CSIR y la Universidad de Stelienbosch en Sudafrica, CIRAD Foret en Francia. CIS-Madera en Espana. CSIRO y CRC-SPF en Australia, el Forest Research Institute Ltd, en Nueva Zelanda e INFOR en Chle.

Sin ernbargo, se trata de un mercado reciente, que según Flynn (2005), Nollan et ai. (2005) y Donnelly et al. (2003), representa una derta mundial de rolkzos asemrables de eucalipto de plantaciones del orden de los 3 millones de $\mathrm{m}^{3}$ al ario ${ }^{3}$, no obstante se proyecta supere los 10 millones de $\mathrm{m}^{2}$ anuales a partir del ato $2015,10 \%$ del cual corresponderia a rollizos podados de alto valor. Los principales oferentes son Brasil, Uruguay. Argentina, Sudaftica y Australia, paises en que se ha realizado manejo intensivo de las plantaciones a traves de podas y raleos y en los cuales la rentabilidad anual promedio de invertif en este tipo de objetivo productivo se ha estimado en el rango de 12 a $24 \%$ (Cubbage ef al. 2005: Nolan et al. 2005, Donnelly et al. 2003), ta cual, según Flynn (2005) supera en muchos casos la rentabilidad real anual que registran los principales fondos de pensiones a nivel internacional.

En el caso particular de la especie E nitens, en Australia Candy y Gerrand (1997) han estimado que la rentabilidad de inwertir en la opcón de alto valor registra una TIR dei $12 \%$ real anual en los mejores sitios de crecimiento, incluyendo en este análisis el costo de uso del suelo. Operativamente. la empresa Gunns Plantation Ltd. (GPL) de Australia ofrece en sus proyectos de inversion (Wocdlot Project) una TIR despues de impuesias de 13.8\% para el esquema de producción de madera para chapas y pulpa con $E$, nitens, considerando una rotación de 20 años, frente al $10,9 \%$ que ofrece para la opción netamente pulpable. considerando una rotación de 13 añost

Chile detecto esta oportunidad y aprovechando sus ventajas ccmparativas para el cultiwo de eucaliptos, en especial con E. nitens, ha iniciado lineas de investigación aplicada. ideradas por el instituto Forestal. INFOR, a traves del proyecto FOUCORFO -Desarrollo de Opciones Productivas de Mayor Valor para Plantaciones de Eucaiyptus nitens en la IX y X Región", ejecutado entre ios arios 2002 y 2004 , en asociación con empresas y productores forestales $y$; ahora con un nuevo proyecto FDI CORFO sobre investigación aplicada en silvicultura para producir rolizos de alto valor, estudio que se ejecutara ente los anos 2005 \& 2007 .

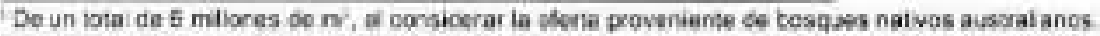

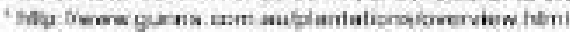


Avalan esta nueva opción productiva la experiencia reciente de algunas importantes empresas del pais, interesadas en diversificar el aprovechamiento industrial de $E$. nitens, incursionando en madera solida, como lo demuestran las exportaciones del año 2004 y de enero - marzo de 2005 entre las que figuran los primeros envios de madera aserrada en tablones realizados por CMPC Maderas S.A., involucrando $1.863 \mathrm{~m}^{2}$ y un monto tctal de US $\$ 242$ mil FOB (INFOR, 2005a y 2005b). En el manejo de plantaciones, Forestal y Agricola Montedguila S.A. tiene proyectado el raleo y poda de 6 mil hectarreas de $E$, nitens de su patrimonio (Herranz, 2005), a lo cual se suma una superficie similar que un grupo de productores del sur del pais tiene proyectado manejar para los próximos cinco años, en predios ubicados en las Regiones $(X)$ y (Ludwig. 2005).

De esta forma. se abre para Chie una nueva opción de inversión y transformacion industrial, representada por el manejo intensivo de plantaciones desde temprana edad, aprovechando el potencial de crecimiento y respuesta al manejo de esta especie y la oportunidad de acceder a un creciento mercado mundial en torno a los eucaliptos. Para los propietarios forestales representa una interesante opcion de inversion, mas aùn en un escenario en que los precios de la madera pulpable de la especie limitan ol desarrollo dei negocio solo a una determinada combinación de condiciones de sito, proximidad a centros de consumo y escala de operaciones, entre otras (INFOR 2004a). De masticarse en Chile la opción de alto valnr para $E$. nifens, significaria que las rotaciones originaimente planificadas sólo para producir madera de aptitud pulpable en tumos cortos, pueden orientarse a la producción conjunta de rolizos para chapas, aserrio y pulpa, con rotaciones de 15 a 20 años según sitio, silvicultura, tecnologias, produclos y otras consideraciones relacionadas con la calidad de la madera, por lo cual se hace indispensable dimensionar su desempeño economico. En este contexto, el presente trabajo se plantea los siguientes cbjetivos:

\section{OBJETIVO GENERAL}

Contribuir con antecedentes e información sobre rentabilidad de imvertir en establecer y manejar plantaciones de $E$. ritens para producir rollizos podados para chapa y aserrio como producto principal y, complementariamente, rolizos aserrables con nudo y pulpables. para las condiciones de crecimiento y costos del sur de Chile.

\section{OBJETIVOS ESPECIFICOS}

Calcular los indicadores de rentabilidad Vaior Neto Presente (VNP), Ingreso Anual Equivalente (IAE) y Tasa interna de Retorno (TIR), para la opción de alto valor con $E$. nitens y de su opción pulpable, bajo dos condiciones de productividad de sitio; con y sin considerar el costo de uso del suelo.

Cacular la rentabilidad de la opción pulpable con E glabulus y compararla con las copciones de alto valor y pulpable de $E$. nifens.

Determinar precios de equiburio para la madera pulpable de $E$. nitens con los cuales se logra la indiferencia entre invertir en la opción pulpabie y la de atto valor con esta especen, y entre la opción pulpable con $E$. mitens y $E$, giobulus 


\section{MATERIAL Y METODO}

\section{Modelo Económico}

Para construir ios tlujos de caja y estimar los indicadores de rentabididad, se alaboro una planilla de calculo en Microsolt Excel. considerando la alternativa de invertir en forestación con E. nitens para dos opciones productivas: a) Alto Valor, orientada a la producción de rolizos podacos, aserrables con nudo firme y pulpable, con una rotacion de 20 afios, y b) Puipabie, considerando dos rotaciones, cada una de 10 ahos. Adicionalmente, para efectos comparativos, al modelo se estructuró para permitir el analisis costo - beneficio de imvertr en la opción pulpable con la especie E. globukus, considerando tambien un flujo de caja de dos rotaciones de monte alto de 10 anos cada una*. Los indicadores Valor Neto Presente (VNP). Ingreso Anual Equivalente (IAF), ambos en dólares? y la Tasa Interna de Retcrno (TIR). fueron estimados empleando las siguientes formulas, obtenidas de Klemperer (1996) y Hubbard et al. ( 1998$)$.

Valor Neto Presente:

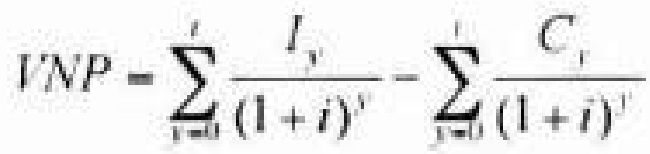

Ingreso Anual Equhalente:

$$
I A E=\left\{\frac{V N P \times i(1+i)^{y}}{\left[(1+i)^{y}-1\right]}\right\}
$$

Tasa Interna de Retcrno:

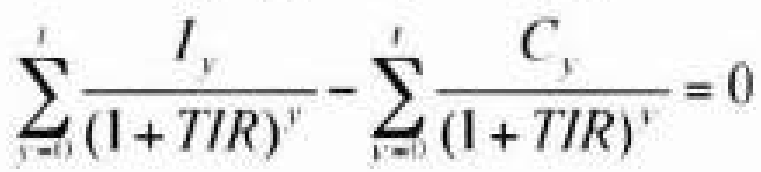

En que:

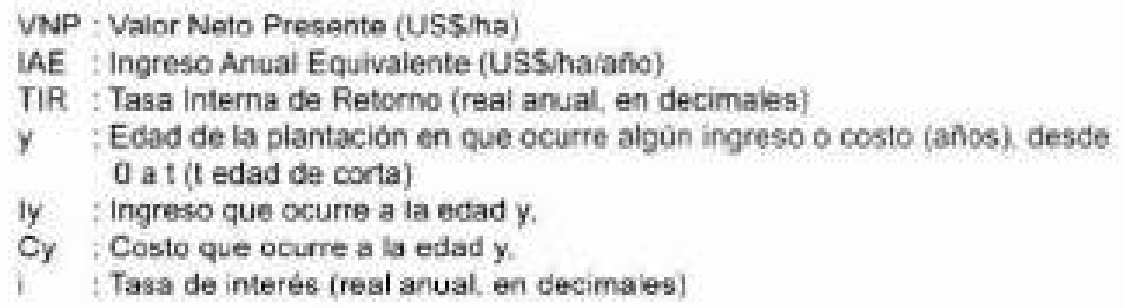

\footnotetext{
Se asimen das rataciones de 10 afos cada una, a clelo de que sean comparablez can la opcion do ato ralor eobro is bave de un mismo perinda de imporsoon de 20 atos:

4 Se asume una sepunda rofacion de monte ailo, considerardo que en 10 ahos, la cardad getefica on las pantas puede legar a usticar enta opoion frente al maneio de los ratenos.

TTpo de cambo observada 1 US\$ = 3581, pramedie matas-abrit-mayu de 2005 (www bceitrul ef)
} 
En todos los casos analizados se determinan los indicadores de rentabilidad para dos productividades de sitio: aita y media, que para $E$. nitens representa el rango de crecimiento observado en la regón de Los Lagos. Los indicadores se estiman con y sin considerar el costo de uso del terreno (compraventa), pero no se inciuye en el anatisis el impacto de eventuales bonificaciones por forestación y manejo. Con respecto a la tasa de descuento, tanto el VNP como el IAE se estimaron considerando un $8 \%$ real anual, magnitud razonable como costo de oportunidad del capital para proyectos forestales que involucran largos periodos de maduración.

\section{Opciones Evaluadas}

Para la opcion de alto valot se considero un 'escuema tipo' ton rotación de 20 anos, derivado de: intormacion generada en el Proyecto FDI CORFO INFOR sobre industria y Mercado, ejecutado el 2002-04 (INFOR. 2004a), información de esquemas australianos (Gerrand et at. 1997): antecedentes recopilados en una gira nacional e internacional, realizadas par el Grupo Nitens de Chile (INFOR 2004b, 2003a); la practica de varios productores de la region de Los Lagos vinculados a proyectos de INFOR y antecedentes de Forestal Mininco S.A. (Dunn, 2003). En la opción pulpable, tanto para E nitens coma $E$ glabintus, se asume la práctica actual, con rotaciones de 10 años. El Cuadro $N^{\circ} 1$ detalla las actividades para ambas opciones, consideradas en el modelo de evaluación. En la opción de alto valor, se aprecia que la oportunidad de los raleos comerciales difiere según productividad del sitio evaiuada (aita y media). En el sitio de alta productividad, el primer y segundo raieo comercial se asumen a la edad de 5 y 10 años, respectivamente; $y$ en el sitio de productividad media, a los 6 y 11 años, respectivamente 


\section{Cuadro $N^{*} 1$ \\ DESCRIPCION DE ACTIVIDADES SEGUN OPCIONES PRODUCTIVAS EVALUADAS}

\begin{tabular}{|c|c|c|}
\hline Ano & Pulpable* & Nhe Valor \\
\hline 0 & 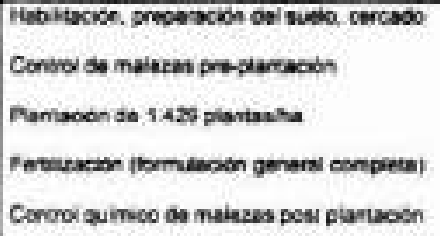 & 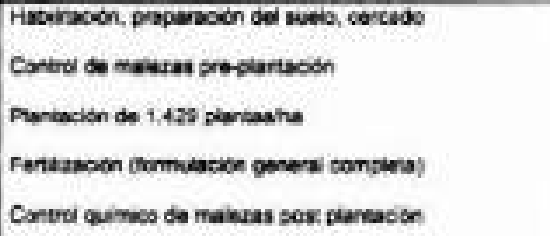 \\
\hline $1-2$ & 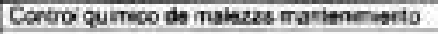 & 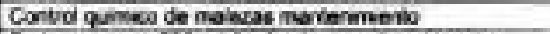 \\
\hline 3 & 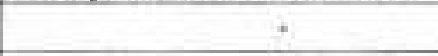 & 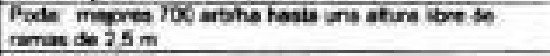 \\
\hline 4 & + & Primer levante poda Sole acha hasia $45 \mathrm{~m}$ \\
\hline 5 & b & 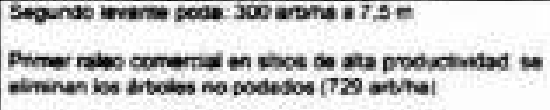 \\
\hline e & + & 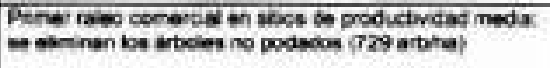 \\
\hline 10 & 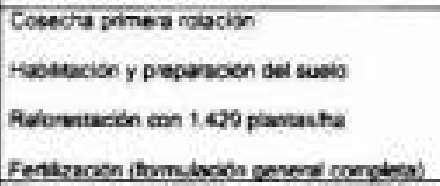 & 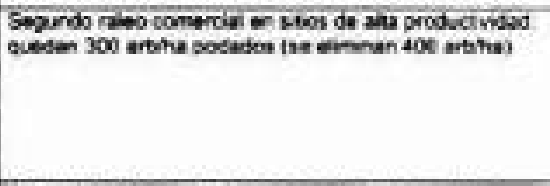 \\
\hline it & Control quinces de nateras martereniente & 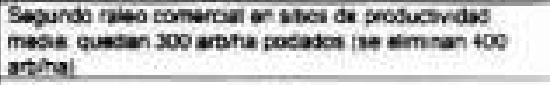 \\
\hline 12 & Comed quinco do nalegas marioninere & 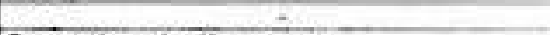 \\
\hline 1029 & 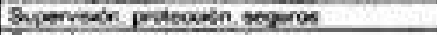 & 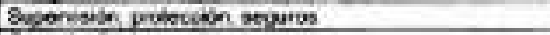 \\
\hline 26 & 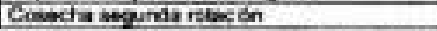 & Cesecta fivai \\
\hline
\end{tabular}

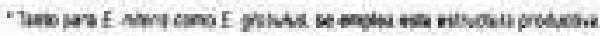

En ambas opciones productivas se asume una misma densidad y tecrologia de establecimiento, no obstante la opcion de alto valor tiene por objetivo principal producir rollizos con madera libre de nudcs, para lo cual considera la ejecución de 3 podas con periodicidad anual, logrando una alture final libre de ramas de $7,5 \mathrm{~m}$ y 2 raleos comerciales, considerando una edad de cosecha 20 aȟos, asumiendo que en las productividades de sitio analizadas, los árboles logran un DAP $\geq 40 \mathrm{~cm}$, que satisface los requerimientos ind ustriales para producir dos rollizos libres de nudos por árbol, uno ciear o multiprcposito de $4 \mathrm{~m}$ y un roliza debobinabie de $2.8 \mathrm{~m}$ de largo, con un diámetro menor minimo de $28 \mathrm{~cm}$ (JAS). Para rollizos aserrables nudosos, se asume un producto industrial de largo $3,35 \mathrm{~m}$ y $18 \mathrm{~cm}$ JAS de diámetro menor minimo'.

'En ausexcia de ascecif́caciones para Eucalicto so ompleo Laa norma para $P$, rochate (Minixce 2000) 


\section{Productividad de Sitio y Rendimientos}

Segùn datos observados por productores y empresas de la regicn de Los Lagos, se estima que el rango probabie de incremento medio anual en volumen (IMA) para plantaciones de $E$. niterns sin manejo, evaluado a los 10 años de edad, fluctüa entre los 30 y $45 \mathrm{~m}^{2} / \mathrm{ha}$ ano", valores consistentes con las proyecciones de los modelos de crecimiento disponibles (INFOR, 2000: Zapata, 2001). En base a las funciones del modolo de crecimiento Euca3.2 por especie, desarrollado por INFOR y considerando una densidad de establecimiento de 1.429 arb/ha, Gichas productividades son similares a las regstradas en indices de stio (IS) de 26 y 33 metros. Para la opción de alto valor, en Chile no exsten herramientas que simulen el crecimiento o información pubicada de rendimientos observados de rodales con poda y raleo, aspecto que INFOR abordara con su nuevo proyecto de silvicultura para la especie. Para superar esta limitante, en este trabajo se asumen volúmenes comerciales para ambos raleos seguin antecedentes productivos de experiencias de manejo en la región de Los Lagos. vajidadas con proyecciones del simulador Euea 3.2 según volumen medio por ábol a is edad del raleo y numero de árboles extraidos, Para determinar el volumen de cosecha final de ta opción de ato valor, se asumio que el volumen total acumulado, incluido raleos, fuese el 90\% del volumen acumulado de dos rotaciones puipables, considerando el IMA de la primera rotación. Para este volumen de cosecha final, en ambos sitios, se asumió que el $40 \%$ es aptitud pulpable; $30 \%$ aserrable nudoso y $30 \%$ rollizos podados (Cuadro $\mathrm{N}^{\circ} 2$ ).

\section{Cuadro $\mathrm{N}^{\circ} 2$}

\section{RENDIMIFNTOS FVALUADOS SEGUN SITIO Y OPCION PRODUCTIVA PARA E, nifens (mha)}

\begin{tabular}{|c|c|c|c|c|c|c|}
\hline $21 T \%$ & \multicolumn{3}{|c|}{ 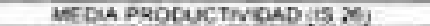 } & \multicolumn{3}{|c|}{ 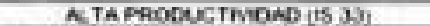 } \\
\hline opcion & Ato Vitor & & & Alev Varor & & \\
\hline Vanacba r acan & & $T^{2}$ macam & $7^{*}$ rutacion & & 10 rakaken & $z$ intacen \\
\hline Volumen reigo 1 & 50 & 0 & 2 & Eo & 0 & 0 \\
\hline Wolumes rateo? & 109 & 0 & $\theta$ & 710 & 0 & 0 \\
\hline INA erias ce crota & 195 & (30 & is & 37 & 45 & 40.5 \\
\hline 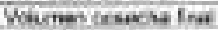 & $3 \%$ & $3 \times$ & 35 & 24 & 450 & 46 \\
\hline Alpatie & 15 & $\infty x$ & 32 & 255 & 450 & 490 \\
\hline Adevidus con nua & $15 ?$ & 9 & 2 & 192 & 0 & 0 \\
\hline Potinde. & $1+7$ & 9 & 9 & 162 & 0 & 0 \\
\hline
\end{tabular}

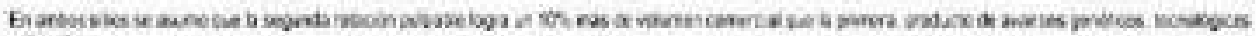
inticat

Para la opción pulpable con E globulus, se asumió un IMA de 20 y $30 \mathrm{~m}^{2} / \mathrm{ha} / \mathrm{a}$ ho, segùn productividad de sitio media y alta, respectivamente" crecimiento que en base a las proyecciones del simulador Euca 3.2 equivalen a un is de 22 y 28 , respectivamente, para una densidad inicial de 1.429 arbiha. Al igual que en $E$. nitens, la segunda rotacion puipable se asume un IMA un $10 \%$ superior a la primera rotación. Estos antecedentes de crecimiento son consistentes con información proporcionada por Prado y Barros (1989), para la Región Ocaànica de Los Lagos. delimitada por los paralelos $39^{\circ}$ y $42^{\circ} \mathrm{S}$, quienes mencionan proyecciones de crecimienio para E globulus sop globuius en el rango de 10 a $29 \mathrm{~m}^{\text {l }}$ /ha: вño. De acuerdo a Geldress y Schilatter (2004), el potencial de E. globulus, de $32,1 \mathrm{~m}^{3} / \mathrm{ha}$ '

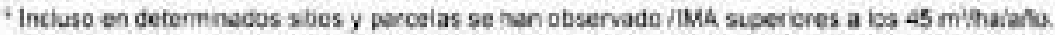

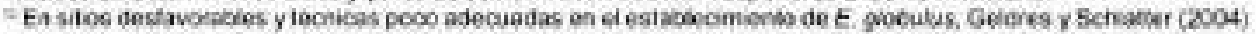

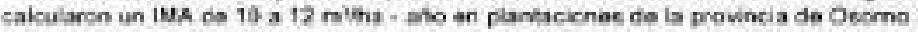


año, medido en una plantación establecida con têcricas adecuadas y ubicada en un sitio favorable, corresponde al crecimiento maximo proyectado para esta zona.

\section{Costos de Establecimiento y Manejo}

Según información de productores de la regón de Los Lagos y los antecedentes de costos de forestación publicados por CONAF (2004) para la temporada 2005, el Cuadro $\mathrm{N}^{\circ} 3$ entrega la magnitud de costos medios de establecimiento y podas empleados en este trabajo

\section{Cuadro $\mathrm{N}^{2} 3$ \\ SUPUESTOS SOBRE COSTOS DE ESTABLECIMIENTO, MANTENIMIENTO Y PODA DE PLANTACIONES DE EUCALIPTO SEGUN OPCION PROOUCTIVA}

(US\$ha)

\begin{tabular}{|c|c|c|c|c|c|c|}
\hline \multirow[t]{3}{*}{ Acovatas } & \multirow{2}{*}{\multicolumn{2}{|c|}{ Dpobn de Asto Water }} & \multicolumn{4}{|c|}{ Osconfrituatis } \\
\hline & & & \multicolumn{2}{|c|}{ Foreitacior } & \multicolumn{2}{|c|}{ Medrastacion } \\
\hline & Ano & |ussthal & $A N=$ & USSha) & ANo & USsha \\
\hline $\begin{array}{l}\text { Mabinacan serado y preparación } \\
\text { nerem }\end{array}$ & 8 & 300 & 8 & हैक & 10 & $150^{\circ}$ \\
\hline Cenio mawas get plantacien & D & 20 & 9 & 00 & 10: & D \\
\hline Punlas y partacion & 0 & 160 & 0 & 165 & 10 & 160 \\
\hline Conoro muesas poett-purvacon & $\frac{1}{D}$ & 75 & 0 & 75 & 70 & $7 s$ \\
\hline Ferbilacion & $D$ & 190 & a & 102 & 10 & 8 \\
\hline 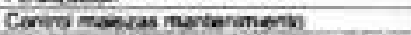 & $1-2$ & $\mathbf{0}$ & $1-2$ & 90 & 12.12 & No \\
\hline 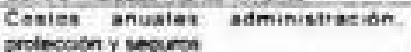 & $1=20$ & $x$ & 7016 & 20 & $11 \times 20$ & 30 \\
\hline Prmer rowa & 3 & 75 & 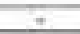 & $=$ & 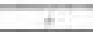 & $\div$ \\
\hline Sopinda post & 4 & 50 & - & 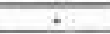 & 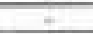 & + \\
\hline Tecerd pods & 5 & 25 & $=$ & $=$ & 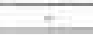 & 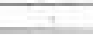 \\
\hline
\end{tabular}

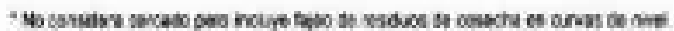

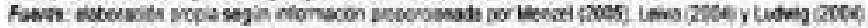

\section{Costo de Adquisición y Precio de Venta del Suelo}

Para incluir el costo de uso del suelo se empleó precios de la tierra diferenciados según productividad de sitio. 950 y 1.300 US\$ha para sitios de productividad media y alta fespectivamente, que son promedios representativos del valor que, a la fecha, alcanzan los suelos de aptitud forestal en el sur del pais (Ludwig, 2005). En ambos casos se asume el mismo precio real de compra (al año 0) y venta (al año 20), con lo cual se considera sóbo los intereses que se dejan de percibir por este concepto.

\section{Costos de Cosecha y Transporte}

Segûn aniecedentes proporoionados por productores del Grupo Nitens (Bregar 2005 Ludwig, 2005: Menzel, 2005) y de calculos realizados por Provoste (2004) para cperaciones de cosecha de E. nitens, se empleó un costo de 15,7 US\$ $\mathrm{m}^{2}$ ssc como valor promedio uniario, el cual considera cosecha y carguio por 7,2 US\$ $/ \mathrm{m}^{3}$ y 8,5 USS $/ \mathrm{m}^{3}$ para transporte. asumiendo un fiete corto de $5 \mathrm{Km}$ y un fete de $80 \mathrm{Km}$ desde el bosque al centro de consumo. Si bien en una misma piantacoón pueden existir diferencias antre costos unitarios para la extracción de madera de raleo y cosecha final y segùn la cimensión de ios productos (chapa. 
aserrio y pulpa), este trabajo las omile para simplificar la estructura del modelo económico y el andisis"

\section{Precio de Productos}

El análisis econámico de ambas cociones productivas, considera la venta de rollsos puestos en planta asignando para ello los siguientes precios por tipo de producto: \$21,000 por metro ruma de madera rolliza puipable de $E$. nitens, lo que equivale a 23,4 US\$/m'ssc ${ }^{12}$, y que es consistente con las estadisticas de precio publicadas por INFOR (2003b) y con el precio del mercado interno que están recbiendo algunos productores de la región de Los Lagos.

Para los rollizos aserrables con nudo y podados de $E$. nitens, dado que no existe un mercado interno establecido, como supuesto se asume los precios puesto planta para la especie pino radiata: 35 y 55 USS $^{-1}{ }^{3}$, respeclivamente. Al respecto, es importante mencionar que el precio que recibira el productor por sus rollzos de ata calidad de $E$. nitens, dependera de una serie de factores, por to que no es factible predecirio; sin embargo, al emplear la magnitud y estructura de precios del mercado intemo del pino radiata como referencia, debiese interpretarse como un escenario prudente, pero conservador para una madera de latifoliada que aspira a acceder a usos de alto valor.

Para la madera pulpable de E. globulus se asumió un precio puesto planta ce $\$ 31.500$ por metro ruma, lo que equivale a 35 USSim 38 cuesto planta ${ }^{\text {. }}$.

En base a los supuestos de costos de cosecha - transporte y los precios puesto planta, en el Cuadro $N^{0} 4$ se consolida los precios de madera en pie utilizados en al análisis de rentabilidad de las opciones descritas.

\section{Cuadro $\mathrm{N}^{\circ} 4$}

PRECIO EN PIE POR TIPO DE PROOUCTO Y OPCION DE NANEJO

(U5s/misse)

\begin{tabular}{|c|c|c|c|}
\hline Polleo & $\begin{array}{c}\text { E. Nhens } \\
\text { Opoison Nhe valer }\end{array}$ & $\begin{array}{c}\text { E nilent } \\
\text { Opelion Pulpabas }\end{array}$ & $\begin{array}{c}\text { E giobuhis } \\
\text { Opeibin pulpabis }\end{array}$ \\
\hline Pupabse & 7.7 & 71 & 193 \\
\hline Asertasie nudoso & 193 & 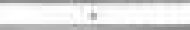 & 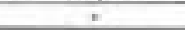 \\
\hline Dadas & 33 & $=$ & $r$ \\
\hline
\end{tabular}

\footnotetext{
- Para ia opeibe de alts yalor se han omedo posbles costcs de pre y post cosecha por twenhuales tratamientos oriertados a mitgar el edecie de las lenaiones de crecimiento de la madera tales come anilamento an prie y use de cerss emulsionartes para é setado de las troibs. putato que a is fecha no se discone de antecedentes para Chile. que efectivamente denwestren su corweniencia.

F Censidera un lactor de cenversión de 1,55 n $^{3}$ per cada meve numa

Zapata (2001) evaluando is remabilidad de dfertries opciones de ssabibcimianto. empled en su anatisis precios puesio piania parz et metro ruma pupstie de $\$ 20 \mathrm{mil}$ para $E$. neens y de $\$ 50 \mathrm{mE}$ para $E$. g6bulus.
} 


\section{RESULTADOS}

\section{Sitio de Alta Productividad}

En ol Cuadro $N^{\circ} 5$ se proporciona los resultados de indicadcres de rentabilidad estimados para una rotación de 20 años de $E$. nitens bajo esquema de alto valor, para dos rotaciones de 10 años con manejo pulpable de E. nitens y para dos rotaciones con manejo pulpable de E. giobuhus. En el caso de E. nitens, los indicadores estimados corresponden a is 33 y en E. giobulus a is 28.

\section{Cuadro Ne 5}

INDICADOFES DE RENTAEILIDAD PARA PLANTACIONES DE E. nitens Y E. globulus SEGUN OPCION PRODUCTIVA, CONY SIN CONSIDERAR EL COSTO DEL TERRENO.

\begin{tabular}{|c|c|c|c|c|c|c|}
\hline \multirow[b]{2}{*}{ opcion } & \multicolumn{3}{|c|}{ Conaideranden eneto Gerrene } & \multicolumn{3}{|c|}{ Sin conalifopar ceste temens } \\
\hline & 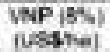 & 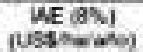 & $\prod_{\langle\mathbf{A}}$ & $\begin{array}{l}\text { WAP (BN) } \\
\text { USAha) }\end{array}$ & 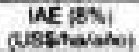 & $\begin{array}{l}\text { TR } \\
(N))\end{array}$ \\
\hline C. npani Ale Yracer & 132 & 175 & 101 & 239 & 79 & 167 \\
\hline E aderu Pucatis & N & 10 & 8.3 & L117 & 114 & 150 \\
\hline F onfous Adootis & $\operatorname{tin}$ & $\operatorname{trs}$ & 127 & 274 & 92 & 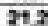 \\
\hline
\end{tabular}

\section{Shtio de Productividad Media}

El Cuadre $N^{*} 6$ entrega resultados de indicadores de rentabilidad estimados para una rotación de 20 ahos de $E$. nitens bajo esquema de alto valor, para dos rotaciones de 10 años con manejo pulpable de $E$. nitens y para dos rotaciones con manejo pulpable de $E$. giobuitus. En el caso de $E$. nitens, los indicadores estimados corresponden a iS 26 y en $E$. globutus a IS 22 .

\section{Cuadro $N^{*} 6$}

INDICADORES DE RENTABILIDAD PARA PLANTACIONEB DE E, nitens Y E. giobukis SEGUN OPCION PRODUCTIVA, CON Y SIN CONSIDERAR EL COSTO DEL TERRENO

\begin{tabular}{|c|c|c|c|c|c|c|}
\hline \multirow[b]{2}{*}{ Opcion } & \multicolumn{3}{|c|}{ 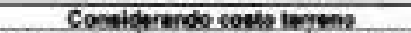 } & \multicolumn{3}{|c|}{ 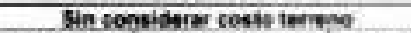 } \\
\hline & $\begin{array}{l}\text { VWP josi) } \\
\text { pesshai }\end{array}$ & 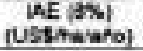 & $\begin{array}{l}T 1 R \\
{[\$ 1}\end{array}$ & $\begin{array}{l}\text { VNP (B)ts) } \\
\text { (USsta) }\end{array}$ & $\begin{array}{c}\text { WE } 18 \% \text { ) } \\
\text { [uSS }\end{array}$ & The \\
\hline E atens ATu Valor & 358 & 3 & 2,1 & 1.109 & 112 & 128 \\
\hline E stari Risation & -49 & -44 & 8.1 & 310 & 12 & 104 \\
\hline E.goburatiopese & sit & 68 & 104 & 1.323 & 142 & 163 \\
\hline
\end{tabular}

\section{Precio de la Madera Pulpable E. nitens para el Equilibrio}

Para una misma condición de sitio (alta o media) y con los supuestos utilizados, el Cuadro $N^{2} 7$ proporciona los resultados del precio equilibrio para la madera pulpable de $E$. aitens puesto planta y en pie, con el cual se iguala el VNP (a un $8 \%$ real anual) de la opcion pulpable frente a la opción de alio valor con esta especie, y el precio con que se logra la indferencia entre invertir en manejo pulpable con E. nifens o con E. globulus iceferis paribusj. an este úlimo caso en la eventualidad que ambos proyectos fuoran mutuamente excluyentes. 


\section{Cuadro $N^{=} 7$}

PRECIOS PARA LA INDIFERENCIA DE INVERTIR ENTRE OPCION PULPABLE CON EnITES FRENTE A OPCION DE ALTO VALOR Y OPCION PULPABLE CON E globulus.

\begin{tabular}{|c|c|c|}
\hline \multirow{2}{*}{$\begin{array}{c}\text { Prscie Pulpabie E nitens } \\
\text { fuSSms aces }\end{array}$} & \multicolumn{2}{|c|}{ Para bualar la Opeide Preductive } \\
\hline & I. nilene Alle Valor & E. piobutys Putpabin \\
\hline Puento fiarta & 30,2 & 20,96 \\
\hline In Pe & is & 12.96 \\
\hline
\end{tabular}

\section{DISCUSION}

La opcion de establecer y manejar plantaciones de E nitens con el objetivo primario de producir rollizos podados para chapas ylo aserrio y de manera complementana madera puipable, considerando rotaciones de 20 anos, es una opción rentable, incluso en sitios de productividad media, siendo una alternativa superior a la opción netamente pulpable. En sitios de alta productividad la TIR de la opción de alto valor fue de 10,8 y $16,2 \%$ real anual, con y sin considerar el costo de uso def suelo durante la rotación, respectivamente. El VNP. para una tasa de descuento del $8 \%$, se estimo en 1.322 y 2.343 US\$/ha, segàn se considere o no ef costo del suelo, determinando un ingreso anual equivalente de 135 y 239 USS/ha, respectivamente.

En contraste la opción de invertir en dos rotaciones pulpables de 10 años cada una con la especie E. nitens en sitios de alta prcductividad, determina rentabilidades inferiores a la opcion de alto vaior, estimándose una TIR de 8,3 y $15 \%$ real anual, segùn se considere o no el costo del suelo, respectivamente. En términos absolutos, considerando una tasa de descuento del $8 \%$, ia opcion pulpable determina un VNP de 96 y 1,117 USS/ha, con y sin considerar el costo del terreno. Se aprecia que en sitios de alta productiridad, la diferencia en magnetud del valor actual de decidir destinar la plantación de $E$ mitens a un objetivo de mayor valor frente a la alternativa de dos rotaciones pulpables, significaria para ef productor incrementar su riqueza actual en mas de US\$ 1.220 por cada hectarea plantada.

En sitics de productividad media. la opción de alto valor con $E$. nitens determina una TIR de 9,0 y $12,8 \%$ según se considere o no el costo de uso del terreno. En estos sitios, la magnitud del VNP a una lasa de descuento del $8 \%$ real anual, se estima en 355 y 1.101 USS/ha, con y sin considerar el costo del sLeio, lo que es equvaiente a una anualidad de 36 y 112 USS/ha durante 20 anos, respectivamente

Invertir en dos rotaciones pulpables con E nitens en sitios de productividad media un tanto, determina rentabilidades inferiorus a la opción de alto valor, estimaindose una TIR. de 6.1 y $10.4 \%$ real anual, con y sin considerar el costo del suelo respectivamente. En términos absolutos, considerando una tasa de descuento del $8 \%$, la opción pulpable determina un VNP de -437 y 310 USS/ha, con y sin corsiderar el costo del terreno. Esto significa que en sitios de productrvidad media, la diferencia en magnitud del valor actual de decidir destinar la plantación de $E$ miens a un objetivo de mayor valor frerte a la opción de dos rotaciones pulpabies. significaria para el productor incrementar su riqueza acual en mas de US\$ 790 por cada hectarea: 
Al comparar $E$ niferis con $E$ giobulis, se aprecia que dos rotaciones pulpables de 10 años cada una con la especie E. giobulus, creciendo a un IMA de $30 \mathrm{~m}^{2}$ halaño, representan una imversión con mayor felomo frente a plantar $E$. nilens bajo un esquema de aito valor, $y$ ambas muy superiores al manejo netamente puipable con $E$, ntens.

No obstante, se debe tener presente que a diferencia de $E$. nitens, la especie $E$. giobuhus no prospera con éxito en terrenos con alta frecuencia $\theta$ intensidad de heladas. situación en la cual no representaria una inversión alternativa. La comparación es correcta en sitios donde E. globulus y E. nitens se desarrollan bien, stuación en que se concluye no debieran primar razones económicas para cambiar el uso de $E$. globuius a $\mathbf{E}$. nitens, salwo que los precios futuros de los rollizos podados de E nitens sean muy supericres a los precios empleados en este trabajo.

Las rentabilidades determinadas son corsistentes con las referencias peoporcionadas por Cubbage et al. (2005). INFOR (2004a) y Donnelly et at. (2003) para plantaciones de Eucalyptus sp en Sudamerica y Chile, y con los resultadcs de Candy y Gertand (1997) para E nifens en Australia. En las mejores condiciones de sitio y crecimiento, y aùn con los precios conservadores utilizados para los rollizos podados, las rentabilidades estimadas para la opción de alto valor superan la rentabilidad anual promedio que han registrado los fondos de pensiones en Chile y de sus rentabilidades esperadas en el largo plazo. A modo de ejemplo, en el periodo 1981 - enero 2005. el promedio de rentabilidad real anual del fondo $C$ fue de $10,25 \%$ (SAFP, 2005), frente at $16 \%$ anual que renta el manejo de alto valor con E nitens en sitios de alta prcductividad.

En sitios de alta productividad y sin considerar el costo de uso del terreno, la opción pulpable con $E$ ailens exhbe una alta rentabilidad, sin embargo al considerar el costo del suelo o cuando se establece en lerrenos de mediana productividad, es una opcon que se encuentra en el limite de la eficiencia económica para este tipo de inversiones, basicamente porque el precio actual de mercado determina un bajo precio de la madera en pie, muy serisible a lcs costos de flese, dejando un margen que aun con el notable crecimiento de la especie. no es suficiente en algunos casos para cubrir los costos de formación y dejar un beneficio nelo atractivo para el inversionista. Por ejemplo, en sitios de alta productividad, la opción puipable de $E$ mitens genera $450 \mathrm{~m}^{3}$ /ha a los 10 años, volumen 1.5 veces superior al registrado en plantaciones pulpables de E. globuîus en sitios de alta productividad; no obstante, la diferencia en la rentabilidad, radica en que el precio en pie de E. giobuius es 2,5 veces superior al E. nitons (19,3 vis 7.7 US\$ $\left./ \mathrm{m}^{3}\right)$. Por ello, la cpcion pulpable con E. nitens sera corveniente solo en terrenos productivos ubicadcs cerca de los centros de consumo, evitando de esta manera ahos costos de transporte que reducen el precio en pie.

En este contexto, y para una misma condición de sitio, se estimo que el precio puesto planta de la madera pulpable de E. nilens que iguala la rentabilidad de la opción pulpable de E nitens con E gíbuvus, es de $28.56 \mathrm{US} \$ \mathrm{~mm}^{2}$, lo que determina un precio en pie de 12.86 USS/m?, frente a los 19.3 de E globulus. Es decir, que el precio en pie de E. globulus puede ser 1,5 veces mayor y aun asi se obtendria igual rentabilidad, ya que se mitga por el mayor volumen de E. nitens, sin embargo hoy en dia este diferencial es muy superior. Similar analisis permitió determinar que con un precio de la madera pulpable de $\mathrm{E}$. nutens de 30,7 USS $/ \mathrm{m}^{2}$ puesto planta (\$27.600 por MR SsC), el productor seria indiferente 
financieramente entre manejar o no las plantacicnes de $E$. nitens, esto considerando que el mayor precio tambien beneficia a la fraccion de volumen pulpabie ce la opción de alto valor.

Finaimente es conveniente recalcar que los supuestos empleados para la opción do alto valor con $E$ aitens, representan un escenario conservador, motivo por el cual los resultados expuestos podrian estar subestimando la rentabilidad de esta ahernativa.

\section{CONCLUSIONES}

El manejo de atho valor de plantaciores de $E$, nufens, orientado a producit rolizos para aserrio, chapas y pulpa, es una opción productiva con alta rentabilidad, que frente a la opcion pupable permite un incremento en el VNF estimado en 1.220 a 790 USSTha, on sifios de productividad alta y media, respoctivamente

En sitos de alta productividad (IS 33), la opcion de alto valor con E. mitens registra una TIR de 10,8 y $16.2 \%$, con y sin considerat el costo del verreno; un VNP $(8 \%)$ de 1.322 y 2.343 USS tha con y sin incluir en el andisis el costo del suelo, respectivamente, io que equivale a rentas anuales de 135 y 239 US\$/ha.

En sitios de productividad media (IS 26), la opción de alto valor con $E$. nitens registra una TIR de 9,0 y $12,8 \%$, con y sin considerar el costo del terreno, un VNP (8\%) de 355 y 1.101 USS/ha, con y sin el costo del suelo, respectivamente, lo que equivale a una renta anual de de 36 y 112 USS/ha, respectivamente

Para concretar dichas rentabilidades, por el lado de la silvicultura se requiere realizar podas oportunas y bien ejecutadas y aplicar un régimen de raleos que permita concentrar el potencial de crecimiento del sitio en un numero apropiado de árboles de cosecha final de alta calidad, con dos o tres rollizos podados. Por el tado del mercado, debe existir una demanda industrial de este tipo de madera, que esté dispuesta a pagar precios similares a los de P. radista para los rollizos de aptitud aserrabie y chapas:

Para una misma condición de productividad de sitio y desde el punto de vista de la economia del productor forestal independente, la opción de ato valor con E. nitens no debiera representar una competencia por uso de suelo forestal con plantaciones de $E$. globulus, donde esta especie logre crecimientas medios por sobre los 20 minaano, salvo que las expectativas de precios de los rollizos podados y/o asemables de E. mitens sean muy superiores a los precios empleados en esle trabajo.

Bajo una misma condición de productividad de sitio y considerando los supuestos empleados en este trabajo, si el precio de mercado de la madera pulpable de $E$ aitens fuera de $\$ 25.700$ por MR (28.56 US\$im'ssc), el productor forestal lograria la misma rentabilidad que con plantaciones pulpables de la especie E. globulus y scbre este precio seria más rentable $E$, nitens. 
Bajo una misma condición de productividad de sitio y considerando los supuestos empleados en este trabajo, si el precio de mercado de la madera pulpablo de $\mathrm{E}$. nitens fuera de $\$ 27.600$ por MR (30,7 US\$/m'ssc), ol productor forestal lograria la misma rentabìdad que invertir en plantaciones de alto valor con $E$. nitens. Sobre esile precio debiera privilegiarse el manejo pulpable.

\section{REFERENCLAS}

Baso, C., 2004. Potencialidand del Eucaryptus globuhus como Madera Solida Universidad de Vigo Escuala Universitaria de Irgeniecia Técrical Forestai, Bolatin de Información Técrica N 228. pp 68-72 http:/infomadera nesinages/19222.pdf

Bregar, M., 2005. Agricola y Foresta: Natahue Ltoa., comunicacion personal

Cabrera, J., 2003. Mercado de E. mitens. Presentacion Seminano Forestal 'Situacian Actual y Proyecciones de Eucaijptus nitens para el Sur de Chile. Valdiva, Agosto. 2003.

http:i/wwwe. infar. c/hwebinforipw-nitens/b-nitens/ndex, htm

Candy; S: Gerrand, A. 1997. Comparison of Financial Rehurns from Sawiog Rngimes for Eucalyphas nitens Plantabons in Tasmania. Tasforests, 9:(35-50).

Corporacion Nacional Forestal CONAF, 2004. Tabla de Castas 2005, www conal cl

Cubbage, F.; Mac Donagh, P; Noemi, M.; Siry, Ji; Sawinski, J.; Ferreira, A.; Hoeflich, V.; Ferreirs. G.: Merales. V.: Rubilar, R.: Alvarez, J.: Donoso, P., 2005. Comparative Timber Inwestment Returns for Selected Plantations and Natve Forests in South America and the Souchern United Stases. Abstract for 2005 SOFEW Conference, Baton Rougn, Louisiana, USA: Agril 18-20, 2005

Donnelly, R.; Flynn, R; Shield, E, 2003. The Globai Eucalyptus Wood Products industry A Progress Report on Achieving Higher Value Utilzation. Brochure. http://www.wrielfd com/PDFs/ Euc\%20brochure\%202003.pd

Dunn, Fe, 2003. Prescripciones Tbenices Pode y Raleos Comerceles en Eucelptus nitens. Subgeranca de Dessarrollo . Fonesta Mninco S.A. Trawui 2003 Mojorando el Negocio Forestal: "Plantando bien ol Pino y el Eucalipto: www.plartex diplantexipresentasionesfernandodunn.pat

Flynn, R., 2005. Eucalyphes: Having an Impact on the Gicbal Solidwood Industry Wood Resources Intemational.

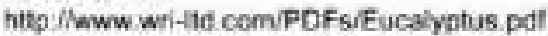

Gaunt, J.; Penellum, B.; Mckenzie, M., 2003. Eucalyptus ntens Laminated Veneer Lumber (LVL) Structural Properties New Zealand Journal of Foresiry Science 33(1) $114-125$ (2002).

Geidres, E; Schlatier, J., 2004, Crecimiento de las plantacianes de Eucalyptus globulus Sobre Suelos Rojo Arcillosos de la Provincia de Osorno, Decima Regon. Note Técnica. Bosque 25/1) 95-101, 2004.

Getrand, A.; Neilsen, W.; Medhurst, J., 1997, Thinning and Pruning Eucalypt Plantations for Sawlog Productian in Tasmania. Tastorosts, 9-115-34).

Herranz, P., 2004. Forestal y Agricola Monteáguila S.A. comuricacion personal. 
Hubbard, W; Abt, R; Duryea, M.; Jacobson, M., 1993. Estmanng the Profitability of Vour NonTember Foresiand Enterprise. University of Florida. IFAS Extension. Circular 836.

fulp-liedis ifas un edu/putiles/FR/FR01500.pdf

Instituto Forestal INFOR, 2000. Modeib de Crecimiento para Eucalipto en Chiln. Avances de Investigacion. Informe Técrico $\mathrm{N}^{\circ} 148$.

Instituto Forestal. 2003a. Misian Tucnológies Australia de Producteres de Eucafypius nitens de la Region de Las Lagos". Documento de Trabajo Intemo, 67 pp. http:/www infor clisebinfor/pw-nitens/b. nitensĭndex.tron

Institute Forestal. 2001b. Boletin de Precios Forestaies. Octubre 2003. 14 pP

Instituto Forestal, 2004a. Eucobyptus nitens en Chile. Econorria y Mercado. Proyecto FDi CORFO Opciones Productivas. Industria y Mercado. informe Tecnico 166.55 pp

Instituto Forestal, 2004b. Giva Nacional 2004 Eucalynfus nitens uma Ophibn de A/ho Vavor para Chile. 11,12 y 13 de agesto de 2004 Documento de Tratajo Intemo, 41 pp.

hitg Jiwwa infor, cliwebirdorlpw-nitensib-ntens index.him

Instituto Forestal. 2005a. Expentaciones. Forestales Chitenas, 2004 . Boletin Estadistice 99.168 pp

Instituto Forestal, 2005b. Exporiaciones Forestales Chinenas

Marzo 2005. Boletin Essadisico. 106 pp

Klemperer, D., 1996. Fores! Resource Econtmics and Finance. McGraw-Hal. 55tpo

Leiva, F., 2004. CEFOR-UACH, comunicacion personaL.

Ludwig, G., 2004. Aaricala y Forestal San Alejandro Lida, comunicacion personal.

Ludwig, G., 2005. Agricala y Forestal San A ejandro Lida , comunicacion personal.

Mckenrie; H: Turner, J.: Shelbeurne, J., 2003. Processing Young Pianiation-Grown Eucalyotus nikens for Solid-Wood Products. 1. Individual-Tree Variation in Qublity and Recovery of Appeararce-Grede Cumber and Veneer. New Zeaiand Journai of Forestry Science 331) 62-78 (2002)

Menzel, M. 2005. Agricela y Farestal El Trebol Lida., comunicacon personal.

Mininco, 2003. Norma de Productos Aserrables para Pino radiala

hitlp:HWw mininco CVIcorpcrativaNORMA ASERRABLE_2003_09.doC

Montagu, K. Kearney, D, Smith, O, 2sa3. Pnunng Fucalypes. The Rigicgy and SAviculture of Clear Wood Praduction in Planted Eucalypls RIRDC Publicaton No 02/152. RIRDC Project No PN.99.2011. wws.riedc govaureportsiAFT/102.152 pdf

Nolan, G.; Greaves, B.; Washusen, R.; Parsons, M.; Jennings, $\mathbf{8}$, 2005. Eucalypt Plantations for Sold Wood Products in Australa - A Review Off you dan z srune it. wi can $\mathrm{r}$ use it: Forest 8 Wood Products Research \& Development Corporation

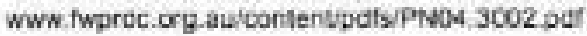

Prado, J. A. y Barros, S., 1989. Eucalyptus Princioios de Silvicultura y Manejo. INFOR-CORFO. 199 P. 
Provoste, F., 2004. Descripcián Tecnica y Econamica de un Sistema de Cosecha Tradicional de Eucalyptus sp con la inccrporación de Dosccrtezado Mecanico en la X Region. Tesis, Universidad Aussal de Chie, Faciulad de Ciancias Forestales, Escuele de Ingenieria Forvstal.

Shitid, Eu 2002. Utilisation of Flartation-Brown Eucelyetus : New Resourcuss -. New Appraaches International Sympceium on Eucalyptus. Plantations Guangzhos - Zhaogng. Guangong. China. Seplember 2002.

Suporintendencia de Administradora de Fondos do Pensiones SAFP, 2005. Exletin Eutadistice N 184 hto: $/$ hwow safp cifint_estadisticalinder htm

Zapata, A., 2001. Efectos de las variables de Establecmiento Inciai en el Crecmenba y la Reritabiidod

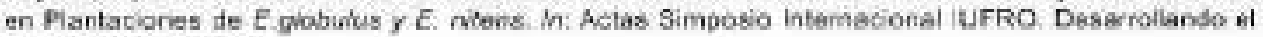
Eucalipto dol Futaro. 


\title{
SILVICULTURA DE PLANTACIONES DE EUCALIPTOS PARA PRODUCTOS DE MADERA SOLIDA DE ALTO VALOR EN EL SUR DE AUSTRALIA
}

\author{
T.G. Baker "2, P.W Volker 2"s
}

\section{RESUMEN}

Australia es el hoger natural de los eucaliptos y hace relativamente poco tiempo el manejo de bosques nativos de aucaliptos para producción de madera sugiere que la necesidad de desarroliar plantaciones de eucaliptos es reducida. En tiempos recientes ha habido dos presiones fuertes que han incrementado las plantaciones con estas especies, La primerg esta dada por un huerte incremento durante los últimos 20 años de àreas designadas como de conservación y excluidas de la actividad forestal comercial, como resultado de decisiones politicas ante la creciente presión de la scciedad. La segunda tarrbiên responde a polificas gubemamentales, Vision 2020, cuyos objetivos buscan triplicar eli area de plantacicnes en Australia a unos 3 millones de hectéreas en el año 2020.

La mayoria de las plantaciones de eucaliptos han sido establecidas en la región templada ed Australa: Western Australia, South Australia. Victoria y Tasmania. Eucalyptus giobulus es la principal especie en superficie y casi todas las plantaciones fienen por objeto la producción de pilpa en rotaciones cortas. En Victoria y Tasmania. como en Chile, Eucalyptus nitens ha sido empleado como sustituto de $E$ globulas, particularmente donde el frio es una limitante para esta última especie.

La creciente reserva de bosques naturales para conservacion, que habian sico b fuente tradicional de madera para aserrio, ha conducido al interes por generar productos de madera sclida con las nuevas plantaciones, sin embargo hay resistencia por parte de la industria a utilizar madera de plantaciones con este fin porque dudan que la madera sea de caidad y que las trozas sean adecuadas para proceso. Se requiere aún mucha investigacion para resolver estas dudas.

Los programas de investigación han evolucionado con el incremento de las plantaciones, inicialmente ta investigacion spunaba a las tecnicas de estabiecmiento cte plantaciones, el mejoramiento de la productividad y de las propiedades de la madera para pulpa, principaimente a traves de genetica y nutricion. En la medida que el interés por la producción de madera sálida ha aumentado, la investigación se ha orientado hacia la silvicultura intensiva con podas y raleos, la durabilidad de la madera y el manejo de plagas y enfermedades.

Este trabajo describe algunos resultados de investigación en silvicultura y propiedades de la madera en el sur de Ausirala y las actuales actividades y ptioridades de investigación. 


\section{SILVICULTURE OF EUCALYPT PLANTATIONS IN SOUTHERN AUSTRALIA FOR HIGH-VALUE SOLID WOOD PRODUCTS}

\section{SUMMARY}

Australia is the natural home of Eucaiyptus, and until relatively recently the management of native eucalypt forests for timber production meant that there was little need to develop a eucalypt plantation estate. In recent time there have been two strong influences which have driven increases in eucalypt plentation establishment. The first has been a large increase over the last 20 years in the area of forest designated as conservation resarves and excluded from commercial forestry activity. This increase has occurred largely as a result of State and Federal Governments decisions in response to increased community pressure. The second influence was the release of the Vision 2020 Policy Statement by the Federal Government in 1897, which aims to triple the area of plantations in Australia to about 3 Mha by 2020.

The majority of the eucalypl plantations have been established in the temperate region of Australia in Western Australia, South Australia, Victoria and Tasmania. Eucalyptus giobulus is the primary species by area, and nearly al plantations are aimed at short rotation pulpwood production. In Tasmania and Victcria, as in Chile. E.nifens has been used as a substitute for E. globulus, particularly where cold temperatures are limiting for the fatter species.

The increased reservation of natural forests, which have been the traditional source of sawnt timber, has led to interest in producing solid wood products from these new aucalypt plantabions. There is resistance to Ltilisation of eucalypt solid wood from plantalions, parfcularty from the processing industry due to concerns about wood quality and processing suitability of the logs. There is still much research required to addross these concerns.

Research programs have evolved with the increase in the plantation estate. Initial research was aimed at establishment silviculture and improving productivity and wood properties of pulpwood plantations, primarily through genetics and rutrition. As the interest in sold wood production increased, research began examining pruning and thinning silviculture as well as wood decay and pest and disease management.

This paper describes some results from silvicultural and wood property research in eucalypt plantations in southern Australia, and current research priorities and activities. 


\section{INTRODUCTION}

Australie is the natural home of Eucatyptus. This genus comprises of over 400 species. many of which are highly valuable for their fibre and timber properties. The ruatural eucalypt forests, which provide the majority of forest produce, comprise approximately 68\% of Australia :s sotal forest cover of 164 Mha. The tall eucalypt forests, which provided the majority of high quality timber and fibre, comprise about $37 \mathrm{Mha}(22 \%)$. These forests are generality harvested for solid wood products from older regrowth (60+ years) to old-growth (up to 450 years). Eucalyptus rograns is an example of one of the species that is utilised extensively for solid imber production. In old-growth natural forests it can reach heights of up to $100 \mathrm{~m}$. Due 10 the magnificent state of hese native eucalypt forests and increasing community pressure for conservation more than half of these highly productive native eucalypt forests have been excluded from comvercial wood production. Federal and State Governments have designated them as conservation reserves in the past 20 years in response to these community concerns. This has resultad in reduction in the availability of high quality hardwood logs, particularly eucalypts, for processing industries. There is a long-established pine plantation resource in Austraka, but it is apparent that there is a continued demand for high quality eucalypt timber in the Australian markel. The challenge for research is to determine the similarites and differences of the new plantation derived timbers with their native forest counterparts.

Australia's plantation esta:e is presently comprised of 1.0 Mha softwoods and 0.7 Mha hardwoods (National Forest Inventory 2005: Figure $\mathrm{N}^{0} 1$ ), a total of about $1 \%$ of the total forest area. In 1997 the Ausiralian Government released its Vision 2020 Policy, which aims to increase the area of plantations by three times by 2020 . resulting in a plantation area of about 3 Mha. Al sbout the same time, governments, large-industrisl growers and vertically integrated pulp and paper companies began to sell their plantation assets. Recent plantaticn development has been driven by Managed Investment Schemes which pool together funds tom smat investors who wish to engage in the business of growing trees and receive the tax benefits avalable to other primary producers. This has resulted in a rapid expansion of plantation area $(0.5 \mathrm{Mha})$ during the last 10 years. This expansion has been dominated by E. globulus planted for pulpwood in southern regions and subtropical species in northem New South Wales and Queensland. 


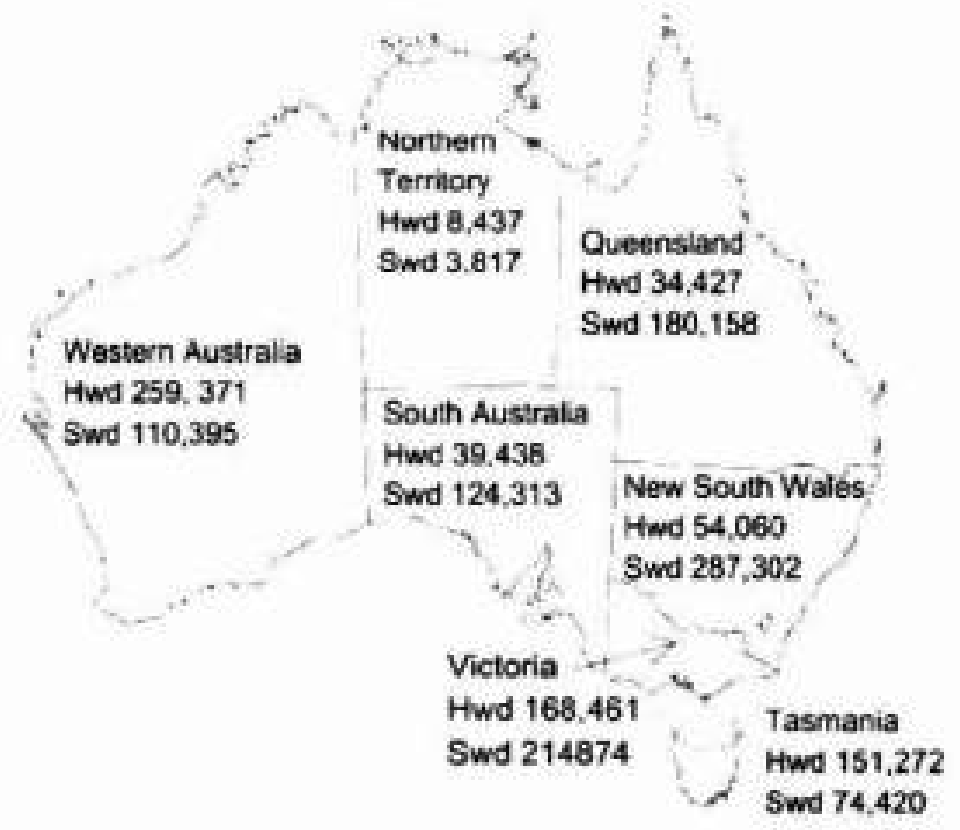

Hwd = Hardwood, predorninantly Eucalyptus spp. Swd = Softwocd, predominantly Pinus spp.

Figure $N^{0} 1$.

\section{PLANTATION AREAS (ha) IN EACH STATE OF AUSTRALIA}

In south-eastern Australia, particularly in Victoria and Tasmania, E. giobuters and E.nitens are the primary plantation species. As in Chile, E. nitens is used where cold temperature limits the use of E. giobuius. The historically important and magnificent $E$. regnans is less favoured as a plantation species cue to difliculties in managing natural pests and diseases and ifs preference for only the highest quality sites. In south-western Westem Australia, and south-eastem South Australia, E. globulus is the most important spocics by area and most plantations are managed for pulpwood with no pruning ar thinning treatment. in subtropical and tropical Australia. the main species planted include E grandis, E piludaris, E. dummit, and Corymbia spp and hybrids, with solid wood regmes being investigated. There is increasing interest in tropical Acacias for fibre producticn and Tectona grandis for timber:

Farm forestry is a developing feature of the Australian rural landscape, especially where there is a tradtion of sawmiling and other industrial forestry activities. The plantation area established by individual landholders (farmers) is much less than that established by state and industrial organisations, but involves a wider range of species (e.g. including $E$. cladocaíyx. C. maculata), oflen in lower rainfall areas $\left(<600 \mathrm{~mm}^{-1}{ }^{-1}\right.$ ) and primarily managed for sawlog procuction. There is also a number of environmental service benefits associated with farm forestry plantations and these are promoled as a secondary benefit of plantasion forestry in agricultural landscapes. 
In Tasmania, the potential for higher-value sawiog and veneer log production from eucalypt plantations over rotations of 20 to 30 years was recognised by Forestry Tasmania the early 1980's. A program of intensive silvicutural management commenced in 1990 (Figure $N^{\circ}$ 2) and is continuing, In recent time, state enterprises and private industry began to adopt simlar regimes in a range of eucalypt species throughoul Australia. There is solil uncertainty abcut the quality of logs and processed products that can be achieved from these plantations (Nolan et at., 2005).

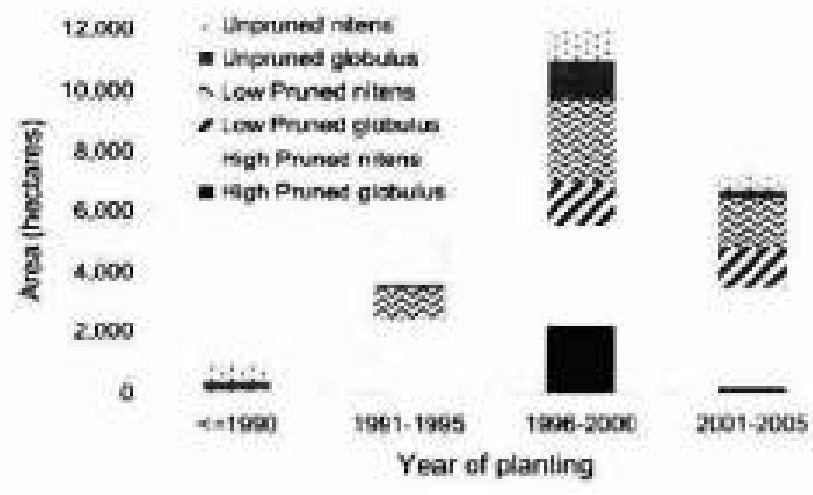

Figurs $\mathrm{N}^{\mathrm{2}} \mathrm{z}$

AREA OF EUCALYPT PLANTATION ANO SILVICULTURAL MANAGEMENT OWNED BY FORESTRY TASMAMIA

It is increasingly recognised that wood production from hardwood plantations for highervalue solid and engineered wood procucts requires a focus on genetic improvement and silvicultural management, (e.g. INFOR, 2004a b; Waugh, 2004; Nutto and Touza, 2004: Nolan et a! 2005). These practices affect the quantity and size classes of logs, incidence of defects (e.g. size of knotty core and spread of wood decay). wood propertes (e.g. tension wood development) that affect processing performance, and serviceability and use of the final product. In Australia, initial research has focused on optimising density (spacing) for yield and control of branch size (Neisen and Gerrand, 1999; Gerrand and Neilsen, 2000; Pinkard and Neilsen, 2003), pruning to achieve knot-and decay-free wood (Wardlaw and Neilsen. 1999: White et al, 1999; Pinkard, 2002) and early thinning to allow more rapid diameter growth of the retained trees to a sawiog size (Gerrand of al., 1997; Stackpolo ef al, 1999. 2004)

Silvicultural research initiated in the early 1980 s is now providing rotation-length results for solid wood regimes and particularly material for processing studies (peeling. sawing and (rying) and utilisation in service.

\section{SILVICULTURE RESEARCH RESULTS}

In Victoria and Tasmanie, growth rates (1otal underbark volumo) of unthinnod $E$, giobulus and $E_{\text {. nitens established at densities of } 1000-1200 \text { trees ha' }}{ }^{\prime}$ in $800-1200+$ mm mean 
annuak rainfall areas, where nutrition is adequate, are typically in the mean annual increment (MAl) range 20 to $30 \mathrm{~m}^{3}$ ha yoar' at age 10 years (Figure $\mathrm{N}^{\circ} 3$ ). Growth rates of $E$. nitens ch the most productive sites approach $50 \mathrm{~m}^{2}$ ha year' $^{\prime}$ and this species is now favored over $E$. regnans on such sites because operational success of establishment with $E$. nitens is more cortain and because of post and disease problems with $E$, rognans.

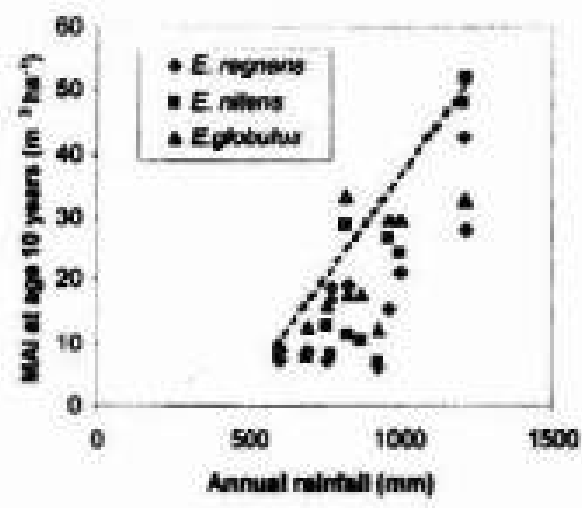

Figure $\mathrm{N}^{*} 3$.

MEAN ANNUAL INCREMENT (MAI) AT AGE 10 YEARS OF UNTHINNED EUCalyphis globulus, E. nitens And E. regnans PLANTATIONS IN RELATION TO RAINFALL. AT TWELVE SITES IN EASTERN VICTORIA, DATA FROM DUNCAN ET AL. (2000).

Growth of E glabubss on some sites with particulariy favourable characteristics is greater than the nominal rainfall envelope limi indicated in Figure $N^{\circ} 3$. For excample, on very deep woll structured soils in the Mediterranean climate of south-western Western Australia, and in south-eastem South Australia where trees can access additional water fe.g. groundwater) by judicious planting in the landscape. Growth can often fall short of the site's potential because of poor management, particulariy pocr control of compoting vegetation and inadequate nutition, and such losses cannot be recovered by later intervention.

Much Australian silvicugural research on eucalypt plantations during the 1990 s aimed to optimize establishment practices for pulpwood production, including studies of soil cultivation (to reduce soil strength; increase aeration, water availability and drainage; and improve tith), weeding (to reduco competition for water, nutrionts and light) and fartiliser application (to avoid nutrient deficiencies and optimise nutrient availability). Genefic research also aimed to increase volume yeids. pulp quality of the fibre, and pest and disease resistance.

The importance of establishment silviculture practices is illustrated for $E$. globulus on a former agricultural (grassand) site in north-eastern Victoria (annual rainfall aporox, 1200 Inm) in Figure $\mathrm{N}^{\circ} 4$, Here, first- and second-season weed control using herbicices was of prime importance, since otherwise early survival was unacceptably low $(<60 \%)$. Whth weeding. the responses to soel cuthivation (nipping to $0.8 \mathrm{~m}$ depth) and $\mathrm{N}$ and $\mathrm{P}$ fertiliser applied at age 
1 year ware additive and continued through to the nominal pulpwood rotation age. The responses to these treatments were surprising since from soll morphoiogical description the soil is apparently well structured, without an impeding layer, and there had been a history of fertliser appication for agriculture.

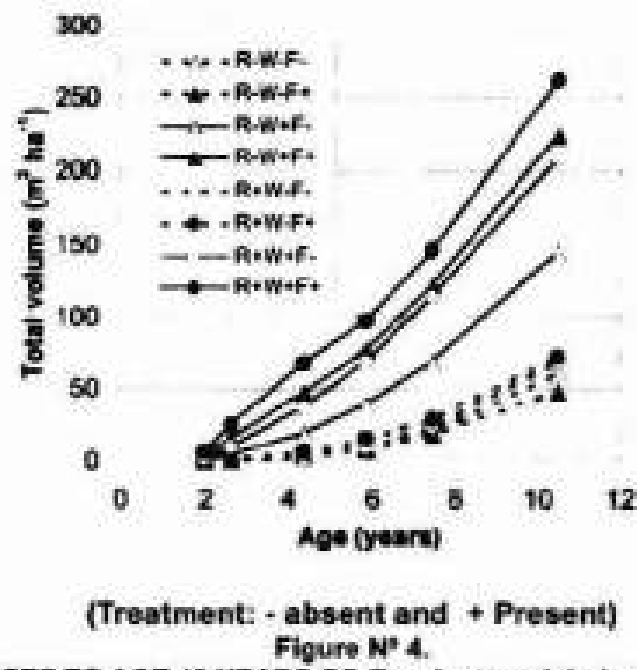

\section{GROWTH RESPONSES TO AGE 10 YEARS OF Eucalyptus globulus TO COMBINATIONS OF} SOIL RIPPING (R), WEEDING (W) AND FERTILISER (F) TREATMENTS APPUED DURING PLANTATION ESTABLISHMENT IN NORTH-EASTERN VICTORIA.

The relative rasponses and therefore the practical importance of establiehment silvicultural practices varies across sites $(0, g$. Duncan and Baker, 2004), and considerable research effort continues to be invested in relating growth to soil physical and nutrient properties, developing rapid methods of measurement of these, and application into models and decision support systems. Good establishment practices will also be the fourdation for management of plantations over longer rotations for solid wood products. With such practices the trees will 'capture' the site rapidly (and recapture the site after thinning), resulting in greater uniformity and better form within the young stand therefore facilitating selection and spacing of trees for pruning. Adequate nutrition during establishment (prior to canopy closure) may reduce early branch senescence and provide for more rapid recovery after pruning

Tending silviculture involves thinning. pruning and fertiliser application to manage the site's biological potential, or the stand's established growth, for a yieid of log product (e.g. saulogs, peeler-logs) that meets market / processor specifications In doing this, protection from or management of interactions / risks with pests, diseases, drought, wind and fire, maintenance of long-term productive capacity of the site and minimization of off-site impacts as assumed.

The primary sikvicultural decisions on initial planting density (stocking) and espacement affect early tree growth (height, form, branch size and senescence). and the seiection ratios 
that can be applied, and therefore planting density interacts with tending practices. Conventionally. thinning practices are concerned with tree diameter distrbutions, tree form and stem shape as they may be affected by timing, intensily and spacing / symmetry of thinning, and impacts on epicormics, upper stem branches and windthrow. Pruning practices are concerned with log defect/ clearwood as affected by timing. intensity. height and diameterover-stubs of pruning lifts. Management of mutrition, by application of fertilisers, is concerned with the growth / vigor of the trees, as aflected by the quantity and timing of application of specific nutrierts. The effects of thinning. pruning and nutrition management may interact. it is increasingly apparant that log and wood properties ralevant to processing performance, such as core to cuter- wood proportions, density and growh stresses (e.g. tension wood) can be impacted or ameliorated by silvicultural practices (e.g. Washusen etfal., 2005).

Conceptually, tending silviculture regimes for solid wood products from larget-scale eucalypt plantations in Australia have aimed to maximize the volume production of highervalue defect free clearwood on large diameter sawlogs and peeler-logs. However, financial imperatives to obtain intermediate revenue(s) from thinnings have required some compromise in practice. Active tending silvicultural regimes that are less intensive and tharefore less costly, and that yield higher volumes per hectare targeted to enginesred solid wood products. have not been explicitly investigated. Tending silviculture practices at the farm forestry or agroforestry scale particularly trade-away total volume production, aiming to produce very high value individual logs, particularly where pulpwood markets are absent or distant.

Competition commences relatively early in fast growing eucalypt plantations established at conventional densities (c., 1000 to 1200 trees ha '). For example, growth responses of the dominant 200 trees ha ${ }^{-}$of both $E$. globulus and $E$. nitens to non-commercial thinning at age 3 years were evident by age 5.5 years on a productive site in north-eastern Victoria (Figure $N^{\circ}$.5a). Furthermore, the growth trajectories of the dominant trees from the thinned treatments (residual densities of 200 and 400 trees ha ${ }^{1}$ ) indicate that inter-tree competition had recommenced from approx. age 6 years.

It is clear that non-commercial thinring reduces total volume production over a rotation. For example in a productive $E$. globulus plantation in south-westem Westem Australia, thinning to 125 trees ha' at age 6 years resulted in approximately half the volume growth at age 15 years compared to the unthinned treatment (Figure $N^{0} 5$ ). The density at which the growth of the selected (and pruned) dominant trees is not affected by competition appears to vary botween sites. In the Western Australian example, the growth of the largest 125 trees ha- in the thinned treatments (residual densities 125 to 500 trees ha ') was the same, and only different from that in the unthinned treatment (Figure $\mathrm{N}^{2} 5$ ). Whereas, growth of the largest 200 trees ha' in E. globulis and E. nitens in the north-eastern Victoria example differed between residual dersities of 200 and 400 trees ha' (Figure $N^{\circ}$ 5a). And more markedly so in $E$. nitens in Tasmania following non-commercial thinning where growth of the largest 200 trees ha 'was different between ireatments with residual densities of 200 and 300 trees ha-1 (Medhurst et al, 2001). The Western Australian example, and other $E$. giobulus experiments on two potentially highly productive irrigated sites in Victoria (Baker et al, 2005; Forrester and Baker, 2005) suggest that where resources (water, nutrients) are relatively abundant a higher fotal density of trees can be retained without loss of growth on the salect dominant trees. 
The evidance suggests site productivity is a factor in selecting a silvicultural regime that optimises volume (or financial) trade-offs between non-commercial thinning and commercial thinning treatments. In E. giobulus and E. nitens in north-eastern Victoria (Figure $\left.N^{0} 5 b\right)$, approximalely one-half to one-third into a nominal $20-30$ year sawlog rotation, the standing volume is such that a commercial thinning yielding approx. 70 to $150 \mathrm{~m}^{3}$ ha: depending on final density, is leasible. The production trade-offs between increased volume and diameter growth on the dominant trees arising from non-commercial thinning, by forgoing a commercial thinning option are evident for both species.

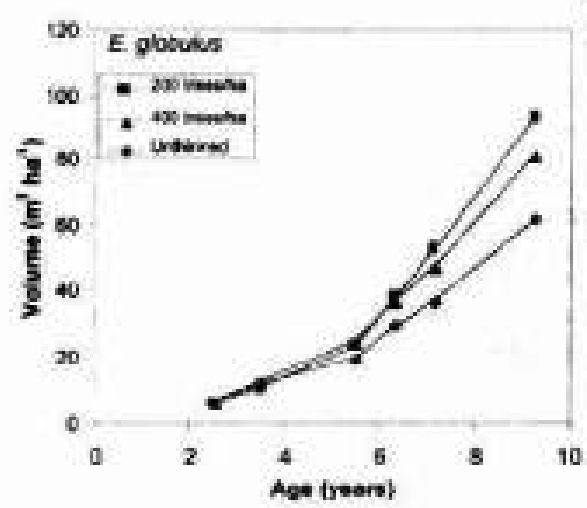

(a)

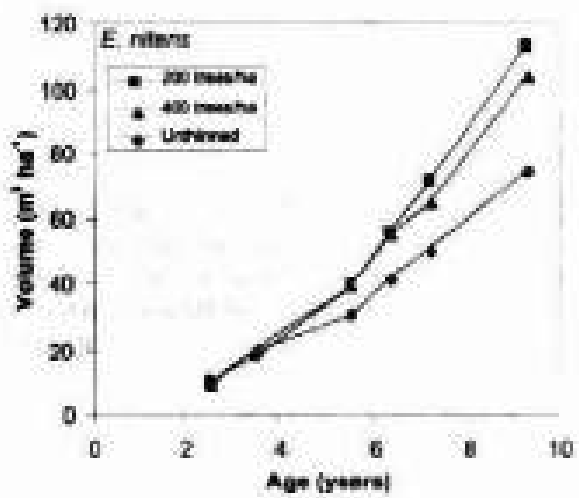

(b)

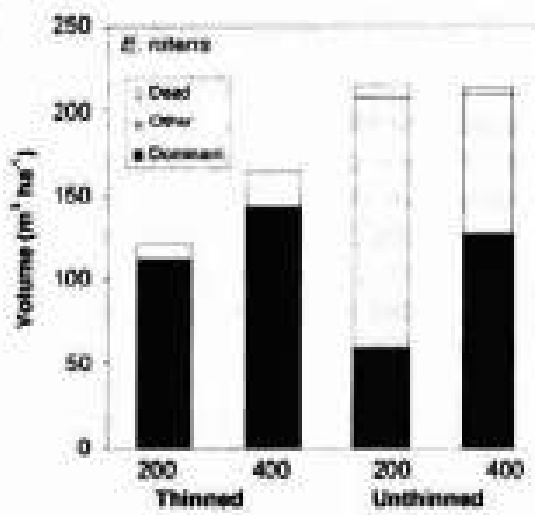

(a) Dominant 200 trees h8' to age 9.5 years and (b) Dominant 200 or 400 trees ha', Other trees and Dead trees at aga 9.5 years.

Figure $\mathrm{N}^{\mathrm{E}} \mathrm{5}$.

VOLUME GROWTH OF Eucalyptus globulus And E, nilens IN UNTHINNFD AND NONCOMMERCIALLY THINNED TREATMENTS (RESIDUAL DENSITIES OF 200 OR 400 TREES ha' AT AGE 3 YEARS) IN NORTH-EASTERN VICTORLA 


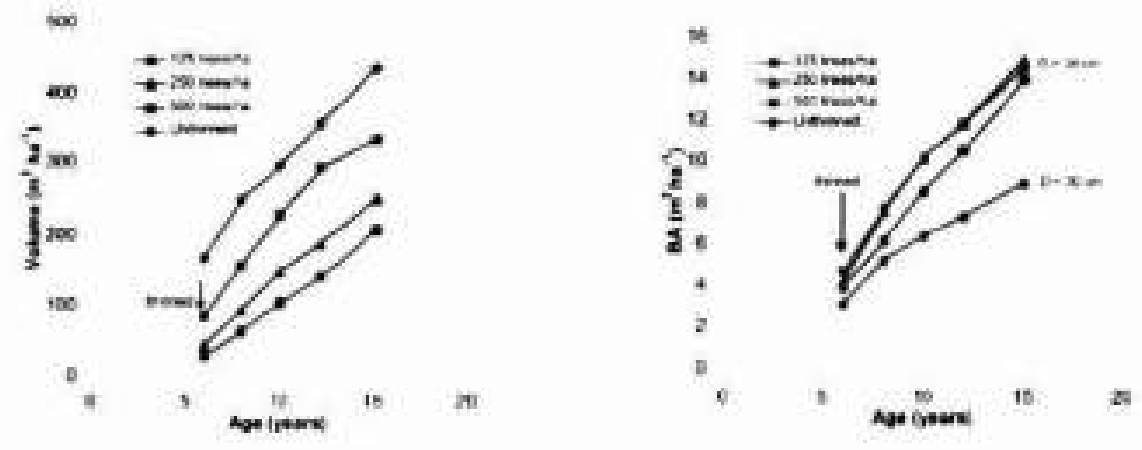

Figure $\mathrm{N}^{*} 5$.

TOTAL VOLUME GROWTH (ALL TREES), AND BASAL AREA (BA) GROWTH OF THE LARGEST 125 TREES ha', OF EUcalyptus globulus IN UNTHINNED AND NON-COMMERCLALLY THINNED TREATMENTS (RESIDUAL DENSITIES OF 125, 250 ANO 500 TREES ha') IN SOUTH-WESTERN WESTERN AUSTRALIA. THE MEAN DIAMETER (D) OF THE LARGEST 125 TREES hat AT AGE 15 YEARS IS INDICATED.

Timely green-branch pruning (ahead of branch senescence) commencing at age 2 to 4 years is essential to achieve clearwood production in these plantations (Montague et al. 2003) and regimes requiring 2 or 3 lifts to a lotal height of $6-7 \mathrm{~m}$ over 3 years can be applied to the dominant trees usually without signiticant disadvantage in either unthinned or thinned stands. From experiments in both $E$. glabulus and $E$. nitens the initial pruning lif: should leave at least $50 \%$ of the green orown length (Pinkard, 2002; Pinkard ef al, 2004). with subsequent ifts to a maximum diameter-over-stubs of $10 \mathrm{~cm}$ (Stackpole et al., 2004). However, there is cantrasting evidenca emerging in operational plantations of $E$. nitens on highly productive sites in Tasmania. On these sites the dominant 350 trees har are pruned in three separate lifts of approximately $2 \mathrm{~m}$ each. If the stand remains unthinned, there is evidence that pruned stems may be suppressed by their unpruned neighbours. This is especially prevalent an sites subject to dejoliation of the upper crown by leat eating insects such as Chrysoptharta bimacuiata.

Current pruning and thinning regimes (Forestry Tasmania, 1998) have been derived from available experimental results supported by some modeiling, principally for $E$. ntens (e.g. Candy ot al. 1997; Gerrand of al., 1993). This has required extrapolation to rotation ages of about 30 years trom availabie results to age $10-20$ years as demensirated in Figure $N^{0} 6$. 

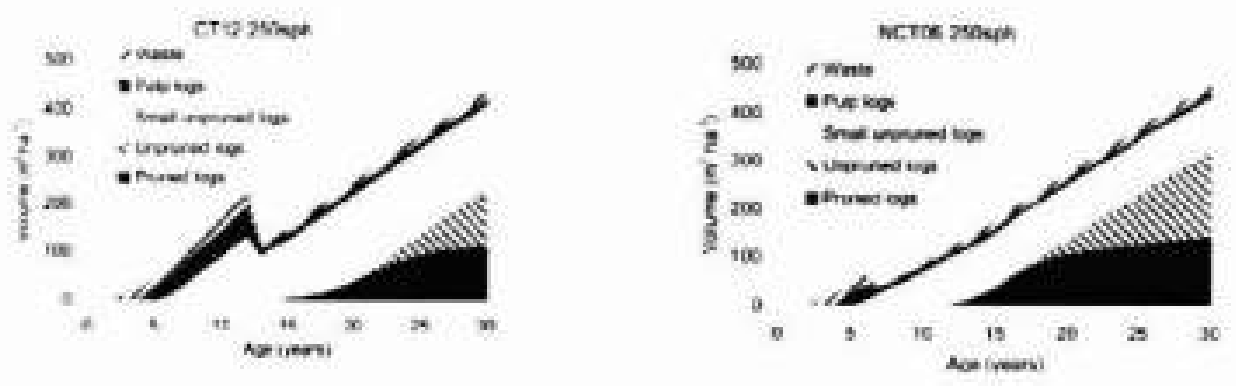

Figure $N^{\circ} 6$.

LOG GRADE YIELDS FROM TWO RECIMES OF EUCalyptus nitens ON A MEDIUM QUALITY SITE IN TASMANIA CT12 250sph IS A CCMMERCIAL THINNING AT AGE 12 YEARS TO 250 STEMS PER HECTARE. NCTOS 250 sph IS A NON-COMMERCIAL. THINNING AT AGE 6 YEARS TO 250 STEMS PER HECTARE, IN BOTH CASES THE RETAINED STEMS HAVE BEEN PRUNED IN THREE LIFTS TO A HEIGHT OF $6.4 \mathrm{~m}$.

Commercial thinning yields can improve the overall financial performance of the regime. Non-commercial thinning has the effect of bringing forward the availability of larger dimension pruned logs. which are usually highly valuable. The results in Figure $\mathrm{N}^{\circ} 6$ demonstrate that there is little difference in the final-harvest vclume of logs produced in both regimes, but the proportion of logs in higher value, larger dimension grades is increased and brought forward by early thinning. This is clearly demonstrated in Figure $\mathrm{N}^{0} 7$ where the MAI of total log value reaches a maximum much eartier than for commercial thinning regimes.

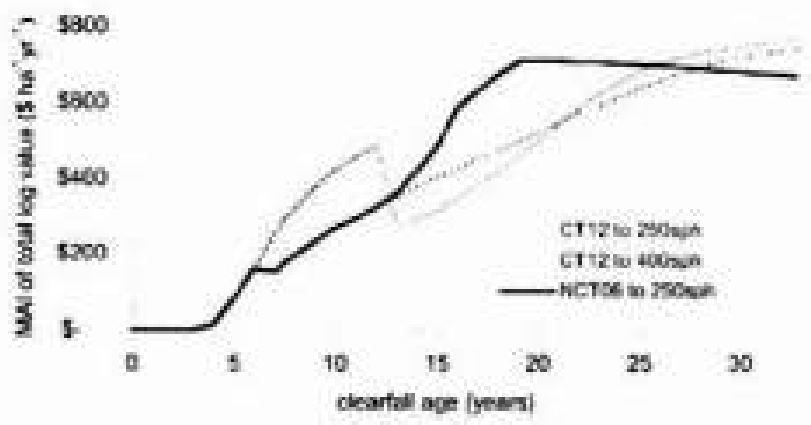

Figure $N^{*} 7$.

MEAN ANNUAL INCREMENT (MAI) OF TOTAL LOG VALUE FOR THREE REGIMES OF Eucalyptus nifens AGE 12 YEARS TO 250 STEMS PER HECTARE. CT12 PLANTATION ON A

MEDIUM QUALITY SITE, CT12 230sph IS A COMMERCIAL THINNING AT 400 sph IS A COMMERCIAL. THINNING AT AGE 12 YEARS TO 400 STEMS PER HECTARE. NCTES 250 sph IS A NON-COMMERCIAL THINNING AT AGE 6 YEARS TO 250 STEMS PER HECTARE, IN ALL CASES

THE RETAINED STEMS HAVE GEEN PRUNED IN THREE LIFTS TO A HEIGHT OF $6.4 \mathrm{~m}$. 


\section{RESEARCH OBJECTIVES}

While there has been relatively enthusiastic uptake of inlensive pruning and thinning regimes for agroforestry or farm forestry, albeit totalling very small areas; the mainstream plantation industry has not generally adopted highwalue solid-wood regimas. The primary limitation is financial. particulary the expected retum on investment compared to alternatives. exacerbated by uncertainties/nsks in volume yieids, log quality and future log prices (Nolan et at., 2005). The current planlation investment structure in Australia favours shcrt rotation (pulpwood) plantations.

Current research is now utilising the products of early pruning and thinning experiments established in young plantations in the sarly $1990 \mathrm{~s}$ (see Gorrand of al, 1997). This work is boing coordinaled across Australia with a number of contributing research and industrial partners through the Co-operative Research Centre for Forestry (CRC Forestry). Recently one of these Eucalyptus nifens pruning and thinning experiments in Tasmania has been harvested at age 22 years. In this expenment, trees were pruned to $6.4 \mathrm{~m}$ and thinning was carried out at age 6 years to residual densities of $400,300,200$ and 100 trees ha.' as well as an unthinned control treatment. The tree dimensions have been measured annually since the experiment was ostablished Logs from the pruned section of the tree have been sawn in both back and quarter sawing palterns. Boards hawe boen kin dried and are now ready for assessment. Prior to and during the harvesting. the trees were measured intensively including diameter at various heights up the stem, crown dimensions (depth and widh) and biomass sampling of various tree components were taken. Non-destructive evaluation techniques have also been used to assess growth strain and wood properties. The aim is to relate these non destructive iechniques to the performance of the processed boards. Tree measurements will be used to bevelop improved growth models for pruned and thinned stands.

There are simiar trials in Tasmania and Victoria in both $E$ nitens and $E$ globulus which can be utirised for further study of the relationship between silviculture, wood properties and product performance of solid wood from eucalypt plantations.

\section{CONCLUSION}

In the first phase of eucalypt plantation development in Australia the primary production objective was to produce puipwood. This was to copture the benefits of increased pulp yield and to supplement the production of eucalypt pulpwood from native forests. Federal and State Government decisions and policies have reduced the amount of native forest available for harvesting. This has led to an increased interest in eucalypt plantations to provide solid wood products that have traditionally been sourcad from native eucalypt forests.

There is doubt thet the piantation resource will deiver the same characteristics in log and wood properties and serviceability of the processed products as that derived from native forests. Research is now examining the best way to manage plantations to produce high quality solid wood for processing. Parallel processing studies are being undertaken using material sourced from these well-designed and managed silvicultural trials. 
The lesson for foresters in this experience is that there is latte understanding in the processing industry of the effects of siviculture on wood properties for processing. There is also a lack of understanding in the wider community that plantations may not deliver the same products and benefits as material sourced from native forests. These are challenges for foresters throughout the world.

\section{ACKNOWLEDGEMENTS}

Results presented in this paper are from studies sponsored by the (Victorian) Department of Primary Industries. Forestry Tasmania. and Western Australia Plantation Resources Pty Ltd. We particularly thenk M. Duncan, D. Stackpole, J. Wiedemann, M. Wood and $Y$ Wang for their contributions to this work.

\section{REFERENCES}

Baker, T., Duncan, M., Stackpole, D, 2005. Growth and Simcuthural Marnagement of ingated Plantabons. in. Now Forests: Wood Productian and Enwwantental Senvices (Eds. Nambiar. S., Forgusan, 1.). CSIRO Publishing Malbourna, pp. 105-126.

Candy, S. G, Gerrand, A. M., 1997. Comparison of Financial Retums from Sawlog Regimes for Eucalyptes nifens Plartacons in Tasmania. Tasforests 9, 35-90.

Duncan, M.J., Baker. T.G., 2004. Earfy-age Cultivation, Weed Control and Fertiliser Resecnses in Eucabyt Plantations on Six Contrasting Stes in East Gippsiand, Victoria. in "Elicalyptus in a Changing Werld" (Eds. N.M.G. Eorratho. J.S. Pereira, C. Matques, J. Cousinho, M. Madeira, M. Tomb) Pg 241. 24s. Proc ILFRO Conf, Avero, 11+15 Oct (RAIZ, Irstituto Invostgaç, da Flonesta e Papel, Portugell)

Duncan, M. J., Baker, T. G. Appleton. R. Stokes, R. C. 2000. Growth of Eucalypt Plantation Species Across Twetre Sites in Gippsiand, Victoria. Report No $99 / 056$, Centre for Forest Tree Technology. Deoariment of Natural Resources and Environment. Melbourne.

Forestry Tasmania, 1998. Prescriptona for Pruning and Thinning Eucalypte in Plantations for Clearwood Production. Division of Forest Research and Develonment, Forestry Tasmania. Hebart

Forrestet, D. L. Baker, T. G., 2005. Growth Response to Thinning in a Productive Eucalyptus globulus Plenterixes in Victoria, Australia, ITTO Intemational Conference on Plantation Eucalyptus Challenge in Preduct Development. Organised by CRCW, CERC, November 28 -Decomber 1, 2hanjang, Guangdong. Chna.

Gerrand, A.M., Neilsen, W.A., 2000. Comparing Square and Rectangular Spacings in Etacalyphis nilens Using a Scolcts Pland Design. Forest Ecology and Martagement 129, 1-6.

Gerrand, A.M., Neilsen, W.A., Medhurst, J.L., 1997. Thinning and Pruning Eucalypt Plantatians for Saviog Production in Tasmania. Tasforests 9. 15-34

Gerrand, A. M., Prydon, R., Fenn, G., 1993. AFinandial Evaluation of Eucalypt Plantatoms in Tasmania Tanlorests 5, 77-97. 
INFOR, 2004a. Eucalyatus nitons en Chile: Procesos industriales de la Madera. informe Tecnico N 164.

iNFOR, 2004b. Eucalyplus nitens en Chie. Primera Manografia Informe Tecrico N 165

Medhurst, J. L.. Beadle, C. L. Neilsen, W. A., 2001. Earty-age and Later-age Thinning Affects Growth, Dominance and intraspecilc Competion in Eucelyptis miteris Plantations. Canadian Jourra' of Forest Reseanch 31, 197-197.

Nelisen. W.A. and Gerrand, A.M., 1999. Growth and Branching Habit of Eucalyntus nitens at Different Spacirgs and the Ellect on Final Crop Selection. Fovest Ecology and Managenent 123, 217-229.

Nutto, L, Touza Vazquez, M.C, 2004 . Produocon de Madera de Seerra de alta Calidad con Eucalyptus glabules Revista CIS - Maddora Numera 12,6-18.

Montague, K. D. Keatney, D. E., Smith, R. G. B., 2003, The Brobgy and Siviculture of Pruning Planted Eucalypts for Clear Wood Production - A Review. Forest Ecology and Manngement 179. 1-13

National Forest inventory, 2005. Nasonal Piantation imventory 2005 Update, Burnau of Rural Sciences. Canberra.

Nolan, G. Greaves, B., Washusen, R., Parsons, M, Jennings, S., 2005. Eucalypt Plantations for Solid Wood Products in hustralia - A.Review. Project No. PNQ4.3002. Forest and Wood Products Plesearch and Development Corporation, Melbourne. favailabie vom www.fwprdciorg au)

Pinkard, E.A. 2002. Fffects of Pattem and Seventy of Pruning on Growth and Branch Development of Pre-canopy Clcsure Eucatyptus ndens. Farest Ecology and Mansgement 157, 217-230.

Pinkard, E. A., Mohammed, C., Beadle, C. L., Hall, M. F., Worledge, D., Mollon, A., 2004. Growth Responses, Physiology and Decay Associated with Pruning Plantaton-grown Eucalyptus globulus Labili. and $E$ nitens [Deane and Maiden] Maiden. Foved Ecology and Manggement 200, 263-277

Pinkard, E.A. and Neilsen, W.A., 2003. Crown and Stand Characteristics of Eucsłyptus nitens in Responset to Iritial Spacing Implications for Thinning. Fonest Eculogy and Management 172. 215-227. Stackpole, D.J., Baker, T.G, Duncan, M.J., 1999. Early Growth Trends Following Non-commercial Thirning and Pruning of Three Partation Eucalypts in Northarn Victoria. pp. 170-175 in Practising Fonestry Today, 1 sth Biennial Conference of the Irstitute of Foresters of Australia. Hobart. Tasmania

Stackpole, D.J., Baker, T.G., Duncan, M.J., Smith, 1.W., 2004, Value-Adding Sitvicultural Regimes for High Quality Timber Production from Intensively Managed Hardwood and Sofiwood Plantations. Project Report PN97,602. Furest and Wood Products Research and Development Corporation, lavadiabie from wive fuprece org au)

Wardlaw, T.J., Neilsen, W.A, 1999. Decay end Other Defects Associated with Pruned Branches of Eucalypdus nidens. Tastortsts $11,49 \cdot 57$

Washusen, R., Baker, T. Ment, D., Morrow, A. 2005. Effect of Thinning and Fertilizer on the Cellilose Crystalite Width of Eucalyptus globulus. Wood Science and Technology 39: 569-578.

Waugh, G., 2004. Growing Eucaryptus globulus for High-quality Sawn Froducts. In Eucalyplus in a Changing Wonlo (Ede. N M.O. Borratho. J.S. Pereira. C. Marques. 2. Coutinto. M. Madeira. M. Tome) 
Pg 78-84. Proc IUFRO Conf. Aveiro, 11-15 Oct. (RAIZ, Irstetuto Investgaçấo da Fleresta e paped. Portugal)

While, D.A., Raymond, C.A, Kile, G,A., Hail, M.F, 1999. Are there Genetic Diferences in Susceptbilly of Eucalyplus nuterns and E. reguans Stems to Defect and Decay? Australan Forestoy 62, 368-374. 


\section{REQUERIMIENTOS DE INNOVACION ESTRATEGICA COMPETITIVA PARA EL SECTOR FORESTAL (1)}

\section{RESUMEN}

Ignacio Cerda V. (2), Carlos Olavarria A. (3), Armando Sanhueza S. (4) y Omar Villanueva O. (5)

Es posible atirmar que el sector forestal debe enfrentar enormes desalios frente a a hipercompetitividad mundial y a la plena incorporacion de Chile al comercio internacional (Tratados de Libre Comercio), por lo tanto, es necesario ampliar la visión sectorial de futuro dada su extrema complejidad, especificamente, por su carácter transgeneracional, sus mpactos ambientales y la importancia del valor ecconómico que "lo forestal" y la industria ce la madera pueden alcanzar. En ese sentido, el Estado juega un papel de primera importancia: dar consistencia y valor estratégico a su accionar es un imperativo que se debe perseguir con el objeto de apoyar e impulsar la activisad sectorial: En efecto, corresponde al pais desarrollar una "estrategia competitiva sostenible" dado el importante potencial que exhite hoy el recurso, en la perspectiva ampliar sus beneficios a los actores sociales imolucrados en su gestion, con pleno respeto al medio ambiente.

Este documento es un resumen de la investigación desarrollada por el instituto Forestal y la Corporacion Nacional Forestal "Requerimiertoe de Innovación Estratcigica Competitiva para ol Sector Forestal'. Le importancis de los resultades obtenides par el peopecto esta determinada por i) Una cobertura muy amplia del sector y cuya proyección de crecimiento, en ferrminos económioos, a fines de esta década puede superar los 10 mil milianes de colares, ii) La identificación de un conjunto de trechas o problemas que se desprenden de una vision sectorial amplia y que representan opertunidades para el diseńo y dictación de politicas püblicas cuyo fin sea reducirios o eliminarios; ii) Los plazos que se ha podido detectar para enfrentar las brechas o problemas, dadas las caracteristicas de largo plazo que tienen los procesos de crecimiento productivo forestal.

Palabras clave: Estrategia competitiva, Innovadión, Brechas

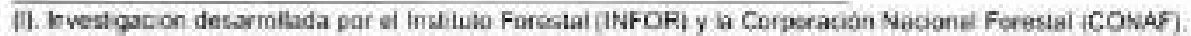

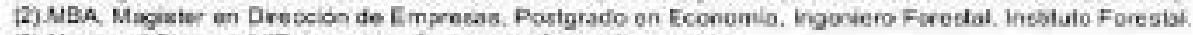

13) Naster a Scence MIT. Ingeniero Camercial. Cribar Cons.diares

i4) hgeniero Foreslal CONAF

15) Ingatiem Cumurnid, Cuntiedar Audinar Consubar Seninur Dibar Consultores.

Asistiones técnicos Cristion Perez y Gonzala Sanchez, ingeneras Foenstalos OaNAF 


\section{SUMMARY}

It is possible to say that the forestry sector must confront huge challenges such as the extreme global competitive environment and the incorporation of Chile to the world trade through free trade agreements, and therefore is is necessary lo widen the sector's future vision given its extreme complexity, specfically due to its cross-generational character, its environmental impacts and the importance in economic value that forestry and wood processing may achieve. In this sense, the state plays a first order role: to give consistency and strategic value to its actions is an imperative which must be sought to support and boost the activity of the secter. Indeed, it corresponds to the country to develop a "sustainable ocmpetifive strategy' given the significart potentia of the forestry resource, within a perspective of widering its benefits to include all the stakeholders and with a deep respect for the environment.

This document is a summary of the research project developed by instituto Forestal and Corporación Nacional Forestal entitied 'Requirements of Competitive Strategic Innovation for the Forestry Sector". The importance of the results achieved is determined by i) A wide coverage of the sector, whose growth projection in economic terms is estimated at over 10 billion dollars by the end of this decode. ii) the identification of a series of gaps or issues that come off a wide sector vision and that represent opportunities for the design and implementation of public polcies whose end be its reduction or elimination, and in) the fimelines. that have been detected to confront the gaps or issues. given the long term characteristics of the production forestry growth processes.

Key words: Competitive Strategic, Innovation, Gaps 


\section{INTRODUCCION}

Con of fin de obtener un marco de referencia, de mediano y largo plazo. para establecer estrategias nacionales destinadas a conservar, manejar y valorzar los bosques chilenos, nativos y plantaciones, asi econo po: la importante inversión en plantaciones ejecutade por el sector privado y el Estado, la Corporacion Nacional Forestal y el Instotuto Forestal desarrollaron esta investigación, cuyo principal propósito es poner en manos de las instituciones de gabierno y del sector privado un conjunto de instrumentos y medicas destinadas a impulsar competitvamente la activided forestal nacional para incrementar su contribución al desarrollo económico, social y ambiental del pais.

Porlos vastos alcances del sector forestal, cuya proyección de crecimiento esperado. en términos económicos (FAO, 2003) del valor de la producción, a fines de esta década puede superar los 10 mil millones de dólares (con tasas sostenidas de crecimiento por sobre el $7 \%$ anual), que sobrepasa ios tradicionales limites de protesiones especificas. Todo ello para establecer de manera fundamentada las brechas o problemas que se desprenden de una visión sectorial amplia, a la vez que estudiar la forma de remover este conjunto de obstáculos, lo que representa oportunidades para el diseho y la dictación de politicas públicas. Se entiende per problemas o brechas a los factoras limitantes que impiden ol desarrollo: estas condicionantes fueron identificadas y descritas por los actores que se consulto o surgieron como producto de las metodologías aplicadas.

Es por ello que para la resolución de taies problemas, la identificación de los plazos (corto, mediano y largo) es importante en la priorización de los temas principales que pueden tener mayor impacto, dada las caracteristicas de largo plazo que tanen los procesos de crecimiento productivo sectorial.

Todos estos aspectos fueron obtenidos mediante una combinacion de instrumentos utilizados en la investigación. La base de información principal surgio do más de 100 expertec naconales y extranjeras conocedores de la actividad nacional forestal. Este trabajo resume las casi dos años labor cuyo informe técrico se encuentra en la Corporacićn Nacional Forestal y ell Instituto Forestal.

\section{OBJETIVOS}

\section{Objetivos Generales}

El objetvo principal es poner en manos de las instituciones de gobiarno y del sector privado un conjunto de madidas que mativen un conjunto de estrategias y politicas. Para ello se empleará un marco de relerencia holistico, de mediano y largo plazo, capaz de proporcionar las bases para establecer las estrategias nacionales destinadas a conservar, manejar y valcrizar los bosques natvos y la importante inversion en plantaciones industriales existentes en el pais. 


\section{Objetivos Espocificos}

Descubrir los factores limitantes que no permiten rablizar el potencial forestal en un concepto de sustentabilidad.

Apoyar con instrumentos base para la generacion de estralegias competitivas y poiticas a los agentes decisionales de cada una de las actividades forestales.

\section{MATERIAL Y METODO}

Para obtener la información que permitiera el logro del objotvo del estudio se diseñó un flujo del proceso de la investigadón que permitiera incorporar secuencialmente fres métodos; Plantoamiento de un Diagnóstico: Método Delfos: y Aplicación de un Sistema Experto, que se explica mas adelante, de manera de cubrir en las dimensiones más amplias al sector forestal chileno. En la figura siguiente se muestra el flujo del proceso de la investigacion y las herramientas utlizadas.

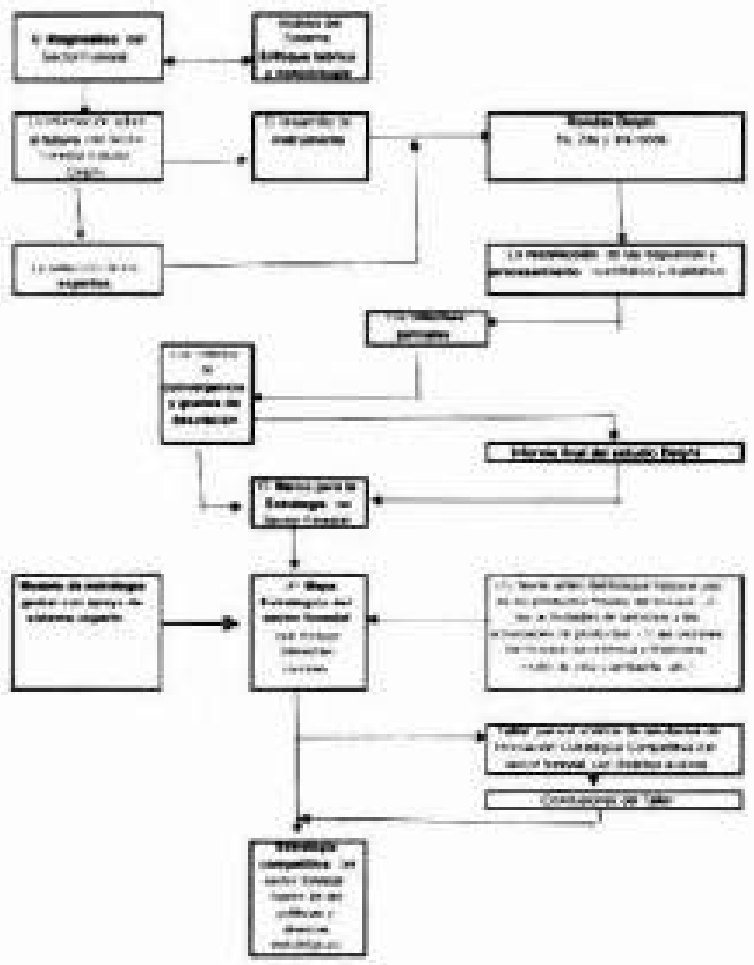


A partir de la aplicación de cada metodologia, su deteclo las brechas o problemas sectoriales más relevanies, las que se usó para fundamentar el planteamiento de orientaciones que sirvan de base a la toma de decisiones gubernamentales en el proceso de generación de politicas publicas para el sector. Se reconcce que una vez que se disponga de estas politicas (Hardner, J. y Rice, R. 1998) será necesario delinear la estrategia para alcanzar los objetivos desesdos, y éstos no son olros que la eliminación o reducción de las brechas detectadas.

De esta manera la Autoridad puede contar con una identificación precisa de ios principales problemas que afectan al sector y algunas ideas para establecer las respectivas estrategias como sustento a su proceso decisional. Ademas. los plazos en que estas estrategias se establezcan juegan un papel relevante en la ayuda para la toma de decisiones. pues facilita la asignación de prioridades para la aplicación de la politica.

Las brechas que corresponden a cada uno de los subsectores de Grandes, Medianas y Pequerias Empresas, para que alcancen caracter de lideres en el ambito global son de largo plazo, van de 20 a 60 afios. Las brechas que dicen relacion con las observaciones entregadas por mis de un centenar de expertos que contestaron el Delfos son de mediano plazo, de 5 a 30 años. Finalmente, las brechas que surgen del Diagnótico son de preferencia de mas corto plazo, van de 5 a 10 arios. Ver anexo I Descripción de la tipologia de empresas

El producto final de la investigación se construyó sobre la base de la información obtenida con la aplicación. en etapas sucesivas, de los tres métodos elegidos, que se scon indicados en forma resumida a contruación:

\section{Diagnóstico}

Es una base descriptiva de la actual situación del sector y una proyección de sus principales cifras de inventarios y de flujos, provee una información adecuada sobre la trayectoria del sector en las ưlimas décadas, sus puntos más reievantes y las tendencias mas destacadas, lo que permile tener una muy buena apreciación del pasado, del presente y del futuro cercano (no mas de 20 anos), de sus principales componentes, sus fortalezas y debilidades, y obtener brechas de plazos relativarnente cortos. El Diagndstico estuvo basado en la información disponible y la experiencia de las dos institucienes gubernamentales ejacutoras, CONAF e INFOR.

\section{Método Dellos}

Es un método que recurre a los conccimientos y a la experiencia de personas vinculadas directa o indirectamente al sector forestal, quienes entregan sus visiones sobre lo que estiman que puede courrir en el futuro en el sector. El ámbito de cotertura del estudo con este mdtodo fue amplio, ya que se realizd consultas a mas de 300 expertos de las empresas productivas y de servicios, de otros sectores industriales en la actividad sectorial, a autoridades de gobierno, a parlamentarios y a academicos de dilatada experiencia. Dichas consultas dieron origen a una base de datos de más de 7,000 eventos, que podrian ocurrir entre el presente y arededor de los años 2010 y 2015, lo que corresponderia a un plazo 
mediano, por la menos en cuanto a la renovación de plantaciones y de crecimiento de diferentes especies.

\section{Sistema Experto}

El sistema muestra claramento la necesidad de enfrentar los temas de largo plazo. sobre 20 años. Se incorpora en el análisis a un sector forestal con tas mejcres practicas mundiales o benchmark, que configura una vision de una meta deseada desde el punto de vista competitivo, y se muestra que alcanzarla sdio es posible en un horizonte de largo plazo. El Sistema es alimentado con informaciòn disponible sobre diferentes subconjuntos del sector forestal, como son las grandes, medianas y pequeñas empresas forestales, con el objeto de determinar la estrategia que está implicita en cada tipo de empresas y se compara con ta estrategia competitiva que debiera tener un Subsector Forestal Ideal o Benchmark. Se completa con información de las grandes y mas importantes empresas forestales qua compiten en el mundo.

La combinación de los 3 métodos se justifica en función de la necesidad de proyectar el futuro esperado de largo plazo del sector forestal

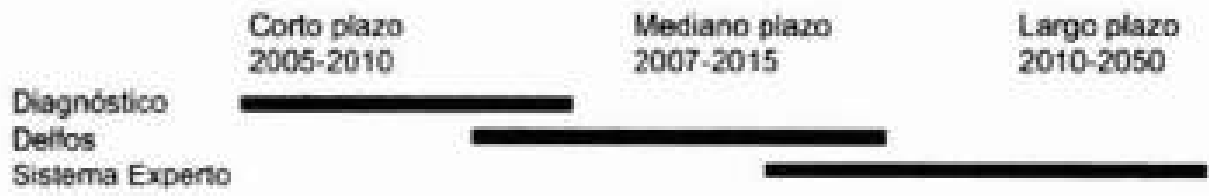

Figura $N^{2} 2$

MATRIZ METODOLOGIA / TIEMPOS DESARROLLO

\section{Las Bases de las Politicas Públicas y sus Estrateglas}

Una politica pública se define como el conjunto de consideraciones jobjetivos. caminos diferentes, mátcolos de acción, etc.) destinadas a determinar opciones de conducta para guiar decisiones presentes y futuras acerca de acciones más o menos especificas (estrategias, planes, programas, proyectos, o asignación de recursos).

Las experiencias con politicas públicas exitosas muestran que su aplicación permite generar áreas de innovación donde existian brechas importantes, permitiendo a la Autoridad escoger los mecanismos más adecuados y al sector privado desarrollar negocios en los distintos segmentos de la cadena de creación valor de un sector económico. Se parte de la base que las politicas públicas son desarrolladas por organismos del Estado preocupados del logro de determinados propositos o finalidades.

Para cumplir con el objetvo se propuso bases de politicas públicas para aquelias materias que pudieran estar sujetas a la decisión del sector público forestal y se enuncib algunas estrategias que se podrian utilizar para su puesta en marcha. 
Cada uno de los problemas o brechas identificados con cada uno de los 3 metodos debla dar nacimiento a la necesidad de formular una politica pública, que debia cumplir algunas condiciones, como por ejemplo, determinar las causas que lo han originado o que lo originarian en el futuro. A su vez, los problemas o brechas debian ser de interés y tener consecuencias para diferentes componentes de la población, distintos de aquellos que las formulan, y se debia determinar las consecuencias favorables que se prevé con la aplicación de la misma.

Se podia pensar entonces en clerentes politicas públicas que se besaran en brechas encontradas en el desarrollo propiamente forestal; bosque nativo o plantaciones. manufacturas sobre la base de maderas, usos alternativos de las tierras forestales. comerciaización de productos y de servicios del sector; vistos desde sus aspectos sociales: eccnómicos, ecológicos. tecnológicos, u otros interesantes de destacar y las relaciones del bosque nacional con ios bosques del mundo en sus diferentes vertientes de colaboracion $e$ impacto.

Por otra parte, la estrategia para aplicar la politica publica corresponde al disento de los procesos de su puesta en marcha, por lo tanso, es la elección de un camino que contiene un conjunto de actividades para alcanzar los objelivos implicitos o explicilas de la politica. Para ello, se hace necesario determinar, por ejemplo, los principales actores o grupos de la población que tienen relación con la politica, que son beneficiados o que pueden ser afectados. - considerar los instnumentos y las unidades administrativas, de estudio y de control que deben existir para la puesta en marcha y su seguimiento.

\section{RESULTADOS}

Del analisis de la información (ver anexo II Sintesis del sector forestal) recopilada se desprende que el sector forestal chileno ha contribuido en forma importante al desarrollo del pais en el campo económico, social y ambiental, y se espera un importante incremento de las ventas y. por ende, un aumento de la contribución sectorial a la economia del pais. todo elo impulsado por la disponbilidad del recurso y por la entrada en vigencia de varios acuerdos de libre comercio, lo que ha provocado mayores volúmenes de negocio y expectativas de parte de todos los agentes sectoriales.

No obstante, el sector presenta un conjunto de factores que entorpecen su marcha futura. Tedos ellos relacionados, principalmente, con la plena incorporación de amplios sectores de la población a quienes no llegan los beneficios del proyecto forestal o maderero, tales como los servicios ambientales, el trabajo y la creación de riqueza. El potencial sectorial es grande $y$, tal como se ha afirmado antes, podria multiplicarse varias veces en el mediano plazo.

Es notable tambien advertir que los grandes temas se encuentran hace ya bastante tempo en la discusion sectorial de varios agentes en forma separada. Por ello, la presentación ordenada y fundamentada tiene el valor de conformar una verdadera guia de desempefo para el Gobierno, que, mediante la administración de politicas públicas, puede impulsar decsivamente el desarrollo sectcrial. 
Los factores limitantes (Hax, A., Majlut, N. 1993) agrupados mas adelante, traspasan los diferentes estadios involucrados en la prcoducción de bienes y servicios sectoriales, a la vez que ponen en consideración los factores sociales, economicos y ambientales que son de su competencia.

Evidertemente no se ha agotado el tema, por el contratio, la tarea más ardua es proponer las medidas concretas, los instrumentos y mecanismos que deben utilizarse para aicanzar los objetivos propuestos. Sin embargo, al definir las brechas y las bases estratégicas para su solución, se proporciona un camino que corresponde ejecutar a la administración para conseguir incorporar mayor cantidad de información a la toma de decisiones.

En varios casos las instituciones püblicas ya han dado cuenta de estas falencias reestructurando sus programas de acción, los que han procurado posicionarse mejor en las problematicas surgidas desde ios analisis de sus actores relacionados, tai es el caso del uso de las metodologias de intervención participativa llevadas cabo por CONAF para el fomento de plantaciones, los planes estrategicos regionales o el levantamiento de un programa de cooperación eficaz para el desarrollo de la industria del muebles de autoria de CONAF, INFOR y ASMAD. En éstos se señala con precisión cuales son las acciones que se debe emprender para, en el mediano plazo, mejorar el accionar de estas àreas del sector.

Sin embargo, también debe señalarse que una gran cantidad de factores limitantes al desarrollo se mantienen intactos y dificultan el crecimiento y ta ampliacion sectorial. Ello da cuenta de la necesidad que el Estado participe con mayor claridad y orden, con el objeto de que la acción abarque la gran mayoria de los factores y en los tiempos requeridos. Los factores limitantes que dificultan ol desarrollo, segün tipologia de empresa, se dosprenden del Analisis del Sistema Experto, futuro de largo plazo. Se concluye que los factores claves de la estrategia de Grandes, Medianas y Pequefias empresas y Benchmark (o situación ideal a nivel mundial) tiene la evaluación representada en la figura $\mathrm{N}^{\circ} 3$

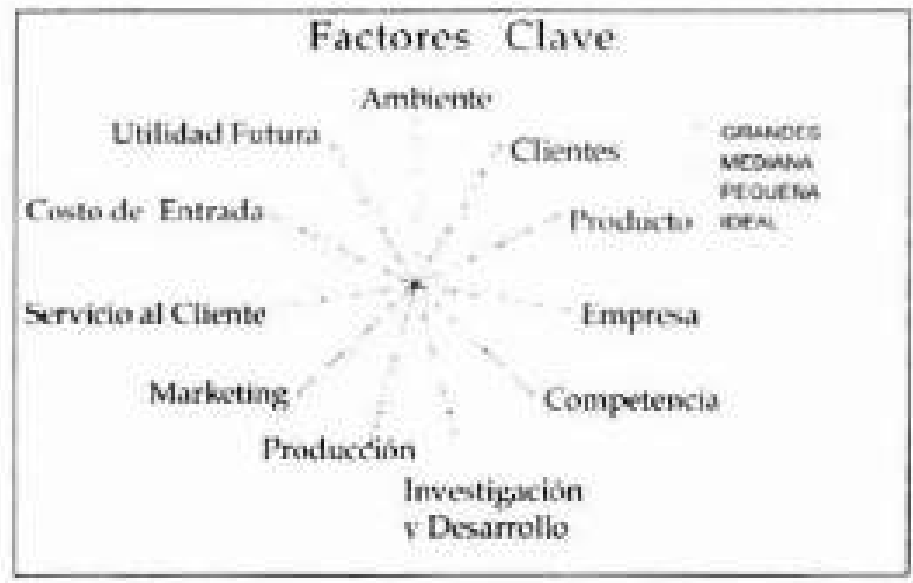

Figura $N^{0} 3$

FACTORES CLAVE PARA LA COMPETITIVIDAD 


\section{FACTORES CLAVE DE LA ESTRATEGIA COMPETITIVA POR TIPOLOGIA DE EMPRESA}

\begin{tabular}{|c|c|c|c|c|}
\hline 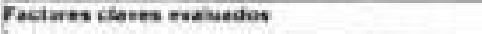 & GALADE & det biank & Requeña & dent \\
\hline Ambirise & 5 A & 65 & st & 92 \\
\hline Cheron: & $6+$ & 57 & 49 & $\phi^{5}$ \\
\hline Frotictos & 54 & 46 & 24 & b] \\
\hline Empressa & 62 & $\mathbf{M}$ & $3 t$ & 99 \\
\hline Cianjetericat & 42 & 40 & 24 & 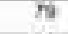 \\
\hline Puetegacion y deswrialn & 56 & 48 & 6 & 97 \\
\hline Produccion & $\pi$ & क्र & 41 & 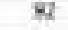 \\
\hline Maretion & 45 & $\$ 6$ & It & 50 \\
\hline Pervicas a dente & Es & 22 & 71 & 4 \\
\hline Covbo de eritexta & 65 & 59 & 32 & 57 \\
\hline Utiont finers & 55 & 49 & 45 & 30 \\
\hline 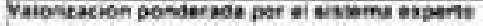 & Se & 51 & 12 & Et \\
\hline
\end{tabular}

Cada una de las lineas del Cuadro $\mathrm{N}^{0} 1$ y sus respectivos casilleros, representa los valores que tienen los 11 factores clave componentes de la cadena de valor para cada tipologia de empresa. La valorización refleja una determinada estrategia compettiva actual que se sigue o que esta implicita en la rea lización de sus actividades regulares. La valorizacion ponderada es el valor promedio que identifica la estrategia giobal por tipo de empresa.

Mientras más cercano a 100 es el valor de un factor clave, más exitosa debiera ser esa parte de la estrategia. Los valores inferiores a 50 significan que ese factor clave o que la estrategia competitiva completa tiene fuertes debilidades para sobrevivir en el madiano o largo plazo.

En el cuadro se puede observar las diferencias de cada factor por tipologia de empresa con el valor del benchmark o ideal. Las diferenclas representan las fortalezas o las debilidades de cada tipo de empresa para competir con exito en el mercado local e internacional.

A su vez. las diferencias encontradas entre la valorización ponderada de cada tipologia estudiada y el benchmark presentan una posibilidad de mejora para tener exito en su futuro desartollo. Ninguna de las variables de los segmentos por tipologias de empresa alcanzo, segun el Sistema Experto, valores cercanos a los de su benchmark. En esto es que puede cater un importante rol a las politicas públicas y sus respectivas estrategias de puesta en marcha, que sean adoptadas por parte de la Autoridad.

Es evidente que si los 3 tpos de empresas no introducen cambios estratégicos que reduzcan sus brechas de debilidades, en el futuro se enfrentan al riesgo de permanecer en el mercado como unas competidoras poco relevantes en el concerto mundial o incluso desaparecer. Lo anterior ya ha ocurrido con cientos de empresas de otros seciores de la economia post global, con grandes oostos económicos, politicos y sociales. 
El analisis estratégico competitivo realizado por el sistema indica, entonces, que aùn se puede introducir acciones significativas en varios estabones de la cadena de valor, que conduzcan, en una primera etapa, a estrategias de nichos o de alta diferenciación. La consecuencia de estos cambios, propuestos a través del Sistema Experto, les puede permitir a estas empresas ser lideres en nichos de mercados diferenciados. En la medida que uno o más nichos de mercados sean bien satislechos a través de sus estrategias concertadas, estaràn mejor preparados para avanzar en la capacidad competitiva.

A modo de resumen, se puede sen̉alar que la conchusion del Sistema Experto, para los negocios tradicionales del sector. se refiere a las estrategias que están en aplicación en cada uno de los 3 segmentos de empresas y su comparación con la estrategia de las empresas lideres del mercado mundial o benchmark.

\section{RECOMENDACIONES RESPECTO A BRECHA Y BASES DE LA INNOVACION}

\section{Recurso}

\section{- Bosque Nativo}

Brecha estratégica: La capacidad productora de bienes y servicios del bosque nativo está muy por debajo de su potencial de uso sostenible, debido a la ceblidad del marco legal bajo el cuar se desenvueive la actividad y la insuficiente investigación que identifique usos altemativos y su demanda. Esto dificulta el cesarrollo de proyectos "madereros", sfectando al abestecimiento regular de materias primas de especies nativas indispensables para la manufactura de productos de mayor valor agregado, y "no madereros" y cen ello la inversión en turismo. salud, ecolurismo o en otros usos paisajistas o de sustentabilidad.

Con esto se ven dantados propietarios de millones de hectáreas de bosques, ia industria de procesamiento, los proveedores y consumidores de servicios, madera y otros.

Base de la politica pública: Impulsar promulgación de ley del bosque nativo para que exista una regulación y fomerto para el abastecimiento de materia prima a empresas manufactureras de productos con valor agregado y otros usos económicos y ambientales.

Base de estrategia de aplicación de la politica pûblica: Creación de una alianza estratégica entre instituciones interesadas en diferentes usos sustentables del bosque nativo. i) Una instancia politica del Estado ii) instituciones gubernamentales de fomento y de desarrollo técnico del sector forestal, iii) Asociaciones de propietarios y de marufactureros de productos que emplean el bosque nativo, iv) Agrupaciones de expertos y profesionales dedicados a materias ambientales y v) Representantes de agrupaciones politicas interesadas en el uso sustentable del bosque nativo. 


\section{- Plantaciones}

Brecha estratégica: Chile dispone de materia prima sostenible en plantaciones, lo que permite incrementar sustancialmente la producción maderera. no maderera y de servicios ambientales. Sin embargo, la actual tasa de forestación resulta insuficiente para utiizar la superficie con aptitud forestal improductiva. Esto se explica, porque en el mediano plazo, la demanda situada por debajo de la capacidad de oferta de estas formaciones hace caer la expectativa del negocio silvicola (plantaciones de pino y de eucaliptos) debido a su baja en rentabilidad, incluida la plantación y su manejo.

Se afecta el futuro desarrollo de plantaciones, mantiene tierras de vocación forestal sin uso, disminuye el valor de la tierra, aumenta las posibilidades de erosión y. por lo tanto, impacta sobre grandes núcleos de la población nacional, sobre los productores independientes en general y especialmente a los mas pequeños. afectando el desarrollo rural y el emplec. Esto encuentra su contraparte en el retraso tecnológico de los pequeños propietarios sivicola. Tambièn tendra efectos negativos sobre su valor intrinseco y el desarrollo de esta actividad y el bosque en el largo plazo.

Base de la politica pública: Priorizar la asignación de recursos y mancomunar la acción pública y privada para concentrarse en areas estratégicas de desarrollo, en plantaciones y manejo de bosque considerando el establecimierto de una sivvicultura superior, la producción de valor agregado en el bosque $y$ la produccion de servicics. Se requiere que el fomento a las plantaciones asuma nuevas modalidaces como la diversificacion, la introducción del mejoramiento genético y la practica de una silvicultura especializada, el incremento del valor agregado en el bosque, la certficación y la participación de la pyme. dado que hay condiciones para incrementar la superficie forestal y mejorar los actuales bosques de los productores independientes.

Base de estrategia de aplicación de la politica pública: Creación de una "alianza estrategica" entre insfituciones que se puedan beneficiar con el fomento de las plantaciones y el desarrclio rural. i) INDAP por ejemplo, ii) Institutos de investigación iii) Instituciones ligadas al desarrollo comunal como municipalidades iv) Una institución de! Estado interesada en investgación y desarrollo, v) Instluciones publicas y privadas, nacionales y extranjeras, que provean fuentes de financiamiento para investigación y desarrollo, como Gobiemos Regonales v] Asociaciones o grupos de empresarios iocales, regionales o nacionales que tienen necesidad de estos resultados.

\section{Desarrollo Cientifico y Tecnológico}

Brecha estratégica. El desarroilo cientifico y tecnologico requiere de nuevas definiciones para contribuir al mejoramiento competitivo del sector. La escasez y dispersión de recursos para la investigación y al desarrolio y la insuficiente disponibilidad de profesionaies 
de alto nivel para incrementar la investigación sistemática sobre los principales temas, dan como resultado investigación sobre parcialidades de los eslabones de la cadena de valor.

La talta de coordinación de la investigación y desarrollo de procuctos, en el campo de nuevos bienes tinales y servicios, el bosque nativo, las plantaciones y la genética para mejorar el rendimiento de las plantaciones y la calidad de la madera, lieva a perder sinergias en el rendimiento económico, social y ambiental del sector forestal

Afecta a los grupos de investigadores, universidades y centros de desarrollo, asi como a proveedores y propietarios de recursos forestales

Base de la politica pública: Priorizar la asignación de recursos y mancomunar la acción pùblica y privada para concentrarse en areas estratégicas, según recomendaciones especificas en eate estudio.

Base de estrategia de aplicación de la politica pública: Creación de una "alianza estrategica' entre instfuciones que se puedan beneficiar con el fomento de la investigación y el desamolo. i) Una institución det Estado interesada en investigación y desarrollo, ii) Instituciones gubernamentales de fomento y de desarrolo técnico del sector forestal, iii) Instituciones públicas y privadas, nacionales y extranjeras, que provean fuentes de financiamiento para investigacion y desarrclio. iv) Instituciones publicas y privadas de investigación y desarrollo y v) Asociaciones o grupos de empresarios privados que tienen necesidad de estos resultados.

\section{Formación de Recursos Humanos}

Brecha estratégica: La educación forestal, es un tema de discusión recurrente en los diagnósticos del sector, requiere de urgentes definiciones, tanto en su nivel de formación tecnica como profesional avanzada, con acento en la necesidad de hacer cambios estructurales en la formación curricular $y$ ampliar el conocimionto hacia otras disciplinas para poder entender mejor las nuavas realidades sociales, tecnicas y ambientales.

En los distintos frentes de acción de la empresa, y en todos sus niveles, hay carencia de personal calificado para enfrentar la función de investigación, desarrollo y adaptación de tecnologias y que, ademas, conozcan y comprendan las nuevas realidades que enfrenta el sector. Estos profesionales son necesarios para incorporar y manejar nuevas tecnologias disponibies para toda la cadena de vaior de la produccion forestal.

Lo anterior limita a las instituciones de educación técnica y superior en su oferta de conocimientos, a los industriales en la disponibilidad de mano de obra calificada, a los actores cue hoy participan de la actividad forestal y, tambien a los posibles entrantes, especialmente to en referido a la evaluación de proyectos en el sector.

Base de la politica pública: La evolución esperada en la producción de bosques. manufacturas ce madera, generacion de nuevos productos y sus mercados debe ser comunicada a los diferentes actores del sector, instituciones de educación técnica superior y 
universidades para realizar las adaptaciones tendientes a proveer personal calificado para los diferentes eslabcoes del sector forestal Un objetivo de la poitica púbilca puede ser tomentar el desarrolio de técnicos y protesionales para las futuras necesidades el sector, de manera de satisfacer las demandas de mano de obra especializada y crear empleos de calidad.

Base de estrategia de aplicación de la politica publica: Mantener une comunicación fluida entre las díferentes actores del sector forestal y las instituciones de educación, sobre los avances y desafios que enfrenta el sector. Una institución deberia asumir la responsabilidad de canalizar los flujos de información y crear puntos de encuentro entre los centros de formación de profesionales forestales y el aparato prcductivo.

\section{Servicios Ambientales}

Brecha estratégica: Los negocios emergentes de los servicios ambientales no cuentar con estrategias y poiticas públicas unificadas. no hay inversión en la magnitud requerida, ni herramientas de fomento que los impulsen. Las acciones actuales son tragmentadas y en función de los grupos emprendedores, ya sean públicos o privados; tampoco hay dispcsición a pagar por parte de otras actividades económicas que usufructúan de los servicios del bosque, por ejemplo, aguas abajo del bosque que regula el ciclo de producción del agua y que asegura su calidad.

A nivel estratégico mas alto se esta siguiendo una estrategia de diferenciación con foco.

La comunidad cientifica ve con interés este fpo de negocio y forma parte del gran debate mundial de la conservación de los recursos forestales

Los negocios ambientales tienen buenas perspectivas para contribuif al desarrolio regional de los propietarios del recurso bosque.

Se carece de instrumentos para el apoyo a los negocios derivados de los servicios ambientales de los bosques.

Hacia el final del periodo se lograria desarrollar el mercado de los servicios ambientales (carbono, regulación hidrica, etc.)

En la evaluación que actuaimente hace el Siatema Experto de esta gama de negocios le asigna 52 puntos ponderados, por tanto existe una brecha de 18 puntos para llegar al minimo fecomendado para una estrategia competitiva.

Base de la politica pública: Se requiere la formación de equipcs mulscisciplinarics; preparar personal de alto nivel para capturar el mecanismo de desarrolio limpio que se aplica en el mundo, diversificar nuevos servicios de clase mundial, estuciar la demanda global por servicios ambientales y desarrollo de su marketing, asociado a los grandes circuitos. internacionales. 